\title{
Data-driven smart sustainable cities of the future: urban computing and intelligence for strategic, short-term, and joined-up planning
}

Simon Elias Bibri ${ }^{1,2}$

\begin{abstract}
Sustainable cities are quintessential complex systems-dynamically changing environments and developed through a multitude of individual and collective decisions from the bottom up to the top down. As such, they are full of contestations, conflicts, and contingencies that are not easily captured, steered, and predicted respectively. In short, they are characterized by wicked problems. Therefore, they are increasingly embracing and leveraging what smart cities have to offer as to big data technologies and their novel applications in a bid to effectively tackle the complexities they inherently embody and to monitor, evaluate, and improve their performance with respect to sustainability - under what has been termed "data-driven smart sustainable cities." This paper analyzes and discusses the enabling role and innovative potential of urban computing and intelligence in the strategic, short-term, and joined-up planning of data-driven smart sustainable cities of the future. Further, it devises an innovative framework for urban intelligence and planning functions as an advanced form of decision support. This study expands on prior work done to develop a novel model for data-driven smart sustainable cities of the future. I argue that the fast-flowing torrent of urban data, coupled with its analytical power, is of crucial importance to the effective planning and efficient design of this integrated model of urbanism. This is enabled by the kind of data-driven and model-driven decision support systems associated with urban computing and intelligence. The novelty of the proposed framework lies in its essential technological and scientific components and the way in which these are coordinated and integrated given their clear synergies to enable urban intelligence and planning functions. These utilize, integrate, and harness complexity science, urban complexity theories, sustainability science, urban sustainability theories, urban science, data science, and data-intensive science in order to fashion powerful new forms of simulation models and optimization methods. These in turn generate optimal designs and solutions that improve sustainability, efficiency, resilience, equity, and life quality. This study contributes to understanding and highlighting the value of big data in regard to the planning and design of sustainable cities of the future.
\end{abstract}

Keywords: Data-driven smart sustainable cities, Sustainable cities, Planning, Design, Wicked problems, Complex systems, Urban complexity, Big data technologies, Simulation models, Urban computing and intelligence

\footnotetext{
Correspondence: simoe@ntnu.no

'Department of Computer Science, Norwegian University of Science and

Technology, Sem Saelands veie 9, NO-7491 Trondheim, Norway

2Department of Architecture and Planning, Norwegian University of Science

and Technology, Alfred Getz vei 3, Sentralbygg 1, 5th Floor, NO-7491

Trondheim, Norway
}

(c) The Author(s). 2021 Open Access This article is licensed under a Creative Commons Attribution 4.0 International License, which permits use, sharing, adaptation, distribution and reproduction in any medium or format, as long as you give appropriate credit to the original author(s) and the source, provide a link to the Creative Commons licence, and indicate if changes were made. The images or other third party material in this article are included in the article's Creative Commons licence, unless indicated otherwise in a credit line to the material. If material is not included in the article's Creative Commons licence and your intended use is not permitted by statutory regulation or exceeds the permitted use, you will need to obtain permission directly from the copyright holder. To view a copy of this licence, visit http://creativecommons.org/licenses/by/4.0/. 


\section{Introduction}

Sustainable cities epitomize complex systems par excellence. As such, they are full of contestations, conflicts, and contingencies that are not easily captured, steered, and predicted respectively. This situation is increasingly compounded by the escalating trend of urbanisation and its negative consequences, as well as continuously exacerbated by the unpredictability of climate change, economic crisis, pandemics, and demographic changes. In short, sustainable cities are characterized by "wicked problems" (Rittel \& Webber, 1973), i.e., their built, infrastructural, environmental, economic, and social problems are difficult to define, unpredictable, and defying standard principles of science and rational decisionmaking. In order to deal with these problems and challenges, advanced forms of ICT are required. New and emerging technologies offer many potentials and opportunities for innovation that can produce a high quality of life and fuel sustainable economic development together with a wise management of natural resources. They are also of critical importance to the understanding of sustainable cities as-dynamically changing environments and self-organizing social networks embedded in space and enabled by various types of infrastructures, activities, and services. These technological advantages are at the core of urban computing and intelligence which, thanks to emerging data-driven technologies (e.g., Batty et al., 2012; Bibri, 2018a, 2018b; Bibri \& Krogstie, 2017; Ji, Zheng, \& Li, 2016; Liu, Cui, Nurminen, \& Wang, 2017; Zhang, Zheng, \& Qi, 2016; Zheng, 2017; Zheng et al., 2015; Zheng, Capra, Wolfson, \& Yang, 2014) can be utilized to improve the performance of sustainable cities and their operation and planning systems, as well as to understand their nature and even predict their future.

The promise that big data science and analytics will revolutionize scientific discovery and technology innovation is now being widely recognized. The abundance of urban data, coupled with their analytical power, opens up for new opportunities for innovative approaches to development planning in sustainable cities. Therefore, sustainable urbanism is increasingly emphasizing the importance of big data technologies and their novel applications in improving and advancing sustainability. This trend is evinced by many topical studies carried out recently on sustainable cities, especially ecocities (e.g., Bibri, 2020a, 2021a, 2021b; Bibri \& Krogstie, 2020a, 2020b, 2020c, 2021; Hakpyeong et al. 2021; Pasichnyi, Levihn et al. 2019; Shahrokni et al. 2014; Shahrokni, Årman, Lazarevic, Nilsson, \& Brandt, 2015; Sun \& Du, 2017; Thornbush \& Golubchikov, 2019; Späth, 2017; Tomor et al. 2019; Yigitcanlar \& Cugurullo, 2020). This implies that the recent advances in urban computing and intelligence associated with monitoring, understanding, analyzing, planning, and managing smart cities are increasingly being adopted by sustainable cities to boost and maintain their performance with respect to sustainability-under what has been termed "data-driven smart sustainable cities" (Bibri \& Krogstie, 2021). In other words, the processes and practices of sustainable urbanism are becoming highly responsive to a form of data-driven urbanism. One of the consequences of datadriven urbanism is that the systems and domains of sustainable cities are becoming much more tightly interlinked and coordinated respectively. And also, vast troves of data are being generated, analyzed, harnessed, and exploited to understand the complex nature of sustainable cities so as to make them safer, cleaner, more liveable, more equitable, more resilient, and, above all, more organized. Indeed, the intersection of big data analytics and complexity science is making it possible to reveal hidden regularities in the organization of sustainable cities. This allows to better anticipate the systemic behavior that result from the many dynamic interactions of all the components that make up sustainable cities. This is necessary for developing advanced simulation models and optimization methods that address new conceptions of how sustainable cities function as complex systems.

However, over the last 50 years, different kinds of simulation models operating at different spatial scales and over different temporal intervals have been used to simulate and predict how cities function and will develop and to estimate the effects of their interventions. The largely focus on "understanding as a prelude to their use to inform the planning and design process" and "simulating the location of physical activities, albeit through an economic and demographic lens that enables material transport and the location of land uses to be predicted using computer models of various sorts" (Batty et al., 2012, p. 497-498). However, the experience of the past decades has shown that the conventional approaches to urban planning and development based on interventions promoting renewed access to urban life have been inadequate to cope with the adverse impacts of urbanization, high population growth, and rapid changes facing sustainable cities. Sustainable cities as complex systems are impossible to plan without having a complete form of knowledge of the consequences of interventions, which evidently is impossible (Marshall, 2012). Accordingly, it is difficult to plan urban complexities through interventions. Moreover, despite the recent advances in urban simulation models (e.g., Batty et al., 2012; Dazhou et al., 2020; Estiri, 2017; Gianni, D’Ambrogio, \& Tolk, 2014; Grinberger, Lichter, \& Felsenstein, 2017; Khan \& Gulliver, 2018; Landis, 2012; Lu et al., 2021; Qin \& Nishii, 2015; Sarkar, Chawla, Ahmad, et al., 2017; Wang, Xu, \& Chen, 2019; Xu et al., 2020) and 
multilevel integrated modelling based on big data analytics, the bulk of work tends to focus largely on smart cities, leaving important questions involving the potential role of these advanced technologies in enhancing the planning and design of sustainable cities.

Data-driven smart sustainable cities pose enormous challenges for both the conventional approaches to planning as well as the conventional forms of simulation models due to the kind of wicked problems and complexities they inherently embody. This is coupled with the very technologies being used to understand their systems in regard to the massive instrumentation, intensive datafication, and large-scale computation pervading the fabric of their environments. In the context of this study, datadriven smart sustainable cities as an integrated and holistic model of urbanism is approached from the perspective of combining and integrating the strengths of sustainable cities and smart cities and harnessing the synergies of their strategies and solutions in ways that enable sustainable cities to improve and advance their contribution to the three goals of sustainability-to protect the environment, secure economic growth, and improve social justice-on the basis of the innovative data-driven technologies and solutions offered by smart cities. Bibri (2021a) provides a comprehensive state-of-the-art literature review of the flourishing field of data-driven smart sustainable cities, including their definitions and dimensions as well as those of the underlying paradigms of urbanism, namely sustainable cities, eco-cities, compact cities, smart cities, data-driven cities, and smart sustainable cities.

The aim of this study is to analyze the enabling role and innovative potential of urban computing and intelligence in the strategic, short-term, and joinedplanning of data-driven smart sustainable cities of the future. This study expands on prior work done to develop this novel model of urbanism in the form of a strategic roadmap towards transformational change (Bibri \& Krogstie, 2021). This model is grounded in the four case studies conducted on the prevailing paradigms of sustainable urbanism and the emerging paradigms of smart urbanism, namely:

- compact cities (Bibri, Krogstie, \& Kärrholm, 2020);

- smart eco-cities (Bibri \& Krogstie, 2020a);

- data-driven smart cities (Bibri \& Krogstie, 2020b); and

- environmentally data-driven smart sustainable cities (Bibri \& Krogstie, 2020c).

The objectives of this study, the four specific steps to be taken to achieve the aim, are:

1. Identify and describe the key strategic planning approaches associated with the built infrastructure of data-driven smart sustainable cities of the future in terms of its compact and ecological designs

2. Map these approaches to the urban fabrics identified based on empirical research and discuss the role of big data in strategic planning.

3. Identify and analyze the evolving innovative approaches to urban planning enabled by the recent advances in urban computing and intelligence.

4. Devise a framework for urban intelligence and planning functions as an advanced form of decision support.

This paper unfolds as follows: Section 2 provides the definitions of the key relevant concepts underlying this study. Section 3 focuses on the literature review in terms of cities as complex systems and characterized by wicked problems, as well as related work. Section 4 briefly introduces and describes the research methodology as regards the case studies informing this study. Section 5 presents the results. Section 6 discusses the results. This paper, ends in, Section 7, with a summary of the key points together with some critical perspectives.

\section{Theoretical background}

\subsection{Urban planning and design}

As a multifaceted process, urban planning focuses on the development, design, and regulation of land use and the built environment, including energy system, water system, waste system, sewage system, green and blue structure, as well as the infrastructure connecting urban areas at multiple levels, including transportation system, communication system, information system, and distribution network. This varied use of urban space focuses on the physical form, economic functions, and environmental and social impacts of the urban environment and on the location and intensity of different activities within it. Urban planning includes social science, architecture, human geography, politics, engineering, and design science.

As a governmental function, urban planning is practiced on the neighborhood, district, municipality, city, metropolitan, regional, and national scales. It has been approached from a variety of perspectives, often combined, including physical, spatial, geographical, ecological, technological, economic, social, cultural, and political. For what it touches on in terms of numerous city-life aspects, urban planning can be broadly categorized into different conceptual areas commonly referred to as types of urban planning, including:

- Strategic planning

- Sustainable planning

- Land-use planning

- Local planning 
- Regional planning

- Master planning

- Environmental planning

- Infrastructure planning

- Urban revitalization

- Economic forecasting

- Community economic development

This study is concerned with strategic planning and sustainable planning, in addition to short-term planning and joined-up planning. These four approaches have many overlaps among them as well as with other approaches, namely land-use planning, infrastructure planning, and urban revitalization. However, strategic planning is the process of setting high-level goals; formulating objectives and targets; developing strategies; making decisions on arranging the means and allocating the resources to pursue these strategies; and implementing, monitoring, steering, evaluating, and improving all the necessary steps in their proper sequence towards reaching the set goals. Sustainable planning is implemented in conjunction with compact and ecological designs and emphasizes the three dimensions of sustainability and their integration, while looking at how development interacts with the surrounding environment in a larger context. The primary goal of urban planning is to achieve the objectives of sustainable development in terms of mitigating the negative impacts on the environment through lowering energy usage, harvesting renewable sources, reducing material use, and minimizing waste, as well as in terms of improving social equity, human well-being, and the quality of life. Ultimately, it seeks to balance the conflicting demands of environmental sensitivity, economic development, social equity, and urban attractiveness and aesthetic appeal. This is at the core of urban sustainability, which represents an ideal outcome in the sum of all the goals of planning, on which there is widespread consensus with trade-offs and conflicts when it comes to decisions. Therefore, urban planning involves policy recommendations, public consultation, public administration, and implementation and management, as well as thorough research and in-depth analysis, and strategic thinking (Nigel, 1998, 2007) to achieve the policy goals of sustainability.

Urban planning involves the application of scientific and technical processes in connection with different city-related components, such as land use, urban design, energy, transportation, waste, and infrastructure. It includes such techniques as modelling, simulation, prediction, geographic mapping and analysis, green condition monitoring, environmental monitoring, power and water supply analysis, transportation and traffic patterns recognition, energy demands and consumption patterns recognition, healthcare services allocation, land-use impacts analysis, and so forth. For example, Geographic Information Systems (GIS) can map the existing urban system and project the future impacts of changes on the environment and the economy. The idea of data-driven smart sustainable cities is to obtain the right amount of data at the right place and from the right source to make well-informed, fact-based, strategic decisions with ease in relation to sustainability using most of these techniques. In this respect, it involves goal setting, data generation, processing, and analysis; modelling and simulation; design, as well as public consultation and citizen participation.

Urban planning is closely related to urban design. Urban design involves landscape architecture, civil engineering, sustainable design, ecological design, compact design, public design, and strategic design. Urban planning focuses on the big picture of the needs of residents and the impacts on surrounding areas, and entails decisions on what can be built where and how outdoor areas will be used. Dealing with the design and management of the public domain and how it is experienced by people, urban design denotes the process of designing, shaping, arranging, and reorganizing the physical structures and spatial organizations of cities and planning for the provision of public services to residents. As to its sustainable dimension, urban design is aimed at making urban living more environmentally sustainable and urban areas more attractive and functional (e.g., Inam, 2013; Larice \& MacDonald, 2007). It is about making connections between forms of human settlements and sustainable development.

\subsection{Urban computing and intelligence}

Urban computing refers to the process of generating, integrating, processing, analyzing, and synthesizing colossal amount of data from heterogeneous sources for some purpose, ways of solving issues related to sustainability, efficiency, resilience, equity, and life quality. In the context of data-driven smart sustainable cities, urban computing entails using a set of sensors, devices, systems, platforms, infrastructures, networks, and the associated algorithms, techniques, processes, and protocols for the purpose of addressing and overcoming the issues engendered by the negative consequences of urbanization and the complex challenges of sustainability. This can be accomplished by manipulating, harnessing, and leveraging various kinds of urban data (e.g., transport data, mobility data, traffic data, spatiotemporal data, environmental data, energy data, socio-economic data, government data, and user-generated data) in ways that generate deep insights which can used to enhance decision-making processes pertaining to diverse urban domains. 
Urban intelligence refers to the planning, development, deployment, implementation, and maintenance of the ecosystem of big data analytics to support the interoperability between resources and technologies-and thus the integration of urban systems, the coordination of urban domains, and the coupling of urban networksto serve the stakeholders of the city. Its functions entail the use of big data analytics and the underlying core enabling technologies to devise more effective solutions in the form of designs and responses using advanced simulation models, optimization methods, and intelligent decision support systems. This requires urban environments to be digitally instrumented to generate the data deluge that enables real-time analysis of the operating and organizing processes of urban life-urban computing. The knowledge extracted as a result of data deluge analytics serves to optimize and enhance the operations, functions, services, designs, strategies, and policies in line with the long-term vision of sustainability thanks to urban intelligence and planning functions as an advanced form of decision support.

Urban computing and intelligence (e.g., Batty et al., 2012; Bibri, 2018b; Bibri \& Krogstie, 2017; Ji et al., 2016; Liu et al., 2017; Lynch \& Del Casino Jr, 2020; Zhang et al., 2016; Zheng et al., 2015) has recently attracted significant attention from academia and industry for building data-driven smart sustainable cities of the future. It represents a holistic approach to harnessing and exploiting the vast troves of big data generated in cities to improve urban forms, urban infrastructures, urban environments, and urban services, as well as urban operational management and development planning systems. As such, it can generate deep insights that can be used to make well-informed decisions, and can also create feedback loops between humans and their activities and the urban environment. Urban computing and intelligence as an interdisciplinary and transdisciplinary field integrates and fuses computer science, information science, data science, urban science, information technology, communication technology, computer engineering, software engineering with city-related fields, including urban planning, urban design, urban sustainability, economy, ecology, sociology, and related subfields.

\subsection{Decision support system}

In the urban context, a decision support system (DSS) is a set of information systems that support city decisionmaking activities. DSS serves the planning, design, management, and operational functioning levels of a city, and helps urban actors make decisions about problems that may be rapidly changing, not easily specified in advance, or of a wicked nature-i.e. unstructured, semistructured, and ill-structured decision problems. It is used to support determinations, judgments, and courses of action and to help decision-makers use communication technologies, data, documents, models, and/or knowledge to complete the tasks of decision-making. Thus, it can be fully computerized, human-powered, or a combination of both. At the technical level, DSS sifts through and analyzes massive amounts of data, compiling comprehensive information from heterogenous sources that can be used to solve problems and in decision-making. This pertains to various urban domains, including transport, traffic, mobility, energy, air and noise pollution, waste, parking, lighting, public safety, healthcare, education, governance, policy, and planning. An example use is GPS route planning. A DSS can be used to plan the fastest and best routes between two points by analyzing the available options. These systems often include the capability to monitor traffic in real-time to route around congestion.

Sprague (1980) describes a properly termed DSS as one that tends to be aimed at less well structured, underspecified problems; attempts to combine the use of models or analytic techniques with traditional data access and retrieval functions; specifically focuses on features which make them easy to use in an interactive mode; and emphasizes flexibility and adaptability to accommodate changes in the environment and the decision-making approach.

With respect to the taxonomies of DSS, the kinds of DSS data-driven smart sustainable urbanism is concerned with are the active and cooperative systems. The former both aids the decision-making process and brings out explicit decision suggestions or solutions (Haettenschwiler, 1999). The latter allows for an iterative process between humans and systems toward the achievement of a consolidated solution. Specifically, the decision-maker can modify, complete, or refine the decision suggestions provided by the system prior to sending them back to the system for validation. Similarly, the system improves, completes, and refines the decision suggestions and sends them back to the decision-maker for validation (Haettenschwiler, 1999). This relates to the kind of DSS that is both fully computerized and human-powered. Another taxonomy for DSS of particular relevance in this context is the one developed by Power (2002), which differentiates data-driven DSS, document-driven DSS, knowledge-driven DSS, and model-driven DSS. These pertain to the various functionalities of the big data analytics system (e.g., knowledge discovery, data mining, statistical analysis, modelling, and simulation, etc.) in the context of data-driven smart sustainable cities with regard to the decision-making processes associated with their operational management and development planning. 
- A data-driven (or data-oriented) DSS emphasizes access to and manipulation of the various parameters of data types in terms of the measurable factor forming one of a set that defines a system or sets the conditions of its operation.

- A document-driven DSS manages, retrieves, and manipulates unstructured information in a variety of electronic formats.

- A knowledge-driven DSS provides specialized problem-solving expertise stored as facts, rules, procedures, or in similar structures. It is most likely to include an expert system or artificial intelligence.

- A model-driven DSS emphasizes access to and manipulation of a statistical, optimization, or simulation model. Model-driven DSS use data and parameters provided by users to assist decisionmakers in analyzing a situation; it is not necessarily data-intensive.

This study is concerned with both data-driven and model-driven categories of DSS in regard to the planning and design of data-driven smart sustainable cities of the future.

Concerning the development framework for DSS, it requires a structured approach. According to Sprague and Carlson (1982), this framework includes people, technology, and the development approach. An iterative development approach allows for the DSS to be changed and redesigned at various intervals. Once a DSS is designed, it will need to be tested and revised where necessary for the desired outcome. However, the early framework for DSS consists of four stages, namely:

- Intelligence-Searching for conditions that call for decision;

- Design-Developing and analyzing possible alternative actions;

- Choice-Selecting a course of action among those actions;

- Implementation-Adopting the selected course of action in the decision situation.

The process starts with the need for the decision. This need can be triggered automatically by the system. Once triggered, the decision task needs to be modeled before any further action. After the model exists, the DSS is able to generate a decision proposal. In the decision-making process, the decisionmaker is able to change which data are used, and possibly the parameters in the model to support the evaluation of the alternatives and the decision on the best alternative prior to adopting the sequence of activities related to the decision.

\subsection{Simulation Models}

One key emphasis of this study is on model-driven decision support systems based on mass data management and analysis. Computational models are used to numerically study the behavior of complex systems by means of a computer simulation. Advancements in computational power, availability of data-intensive modeling and simulation, Artificial Intelligence, and efficient computational methods are allowing the leading-edge of simulation modeling to pursue investigations in systems analysis, design, and control processes in terms of optimization. This pertains to the systems of multiple urban sub-systems (e.g., transport, traffic, building energy, power supply, street lighting, environment, waste, water supply, healthcare, etc.) and their multilevel integration.

The emerging discipline of modeling and simulation is based on developments in diverse areas of computer science (e.g., software engineering, Artificial Intelligence, theory of computation, data structures and algorithms, etc.). It is also influenced by developments in complexity science, data science, urban science, systems engineering, and systems theory. This foundation brings together elements of art, science, engineering, and design in a complex and unique way. This requires domain experts to enable appropriate decisions when it comes to the application and use of modeling and simulation methods within the area of data-driven smart sustainable cities.

The concepts of modeling and simulation are treated as distinctive and of equal importance. A simulation is the execution of a model, represented by a computer program that gives information about the system being investigated. In more detail, modeling is understood as the purposeful abstraction of reality, resulting in the formal specification of a conceptualization and the underlying assumptions and constraints. Simulation is the mimicking or emulation of the operation of a real-world system or process, such as the day-to-day operation of a transport or energy system over a time period in a computer. Accordingly, the model represents the key characteristics or behaviors of the selected system or process, whereas the simulation represents the evolution of the model over time. In other words, modeling and simulation entail the use of models as a basis for simulationsi.e., computational methods for implementing a model to develop knowledge as a basis for decision-making pertaining to, for example, the planning, design, and operational management of data-driven smart sustainable cities.

With the integration of big data analytics, Artificial Intelligence, agents, and other modeling techniques, simulation has become an effective and appropriate decision support tool for planning, designing, and managing urban systems and sub-systems. By 
combining the emerging science of complexity with simulation technology, it has become possible to build software programs that allow city planners, designers, and managers to safely play out "what if" scenarios in artificial worlds and to take decisions to achieve highest performance at lowest cost. In addition to its use as a tool to better understand and optimize performance of systems, simulation is also extensively used to verify the correctness of designs, e.g., urban forms, urban structures, and spatial organizations.

There are two categories of modeling and simulation that are of relevance to data-driven smart sustainable city planning and design, namely (Bibri 2021c):

1. Analyses support is conducted in support of urban planning. Very often, the search for an optimal solution that should be implemented is driving these efforts. What-if analyses of alternatives fall within this category as well. This kind of work is often accomplished by simulysts. A special use of analyses support is applied to urban operations. Simulation methods improve the functionality of decision support systems by adding the dynamic element to them, and also allow to compute estimates and predictions, including optimization and what-if scenarios.

2. Systems engineering support is applied for the design, development, and testing of systems. It can start in early phases and include topics like executable system architectures. It can support testing by providing a virtual environment in which tests can be carried out. This involves the concept of "principle of computational equivalence," which has beneficial implications for the decision-maker, e.g., engineers and architects. Simulated experimentation discovers new insights and explanations of future behavior of the real system. This relates to computational science and engineering, which deals with the development and application of computational models and simulations, often coupled with high-performance computing, to solve complex physical problems arising in engineering analysis and design.

On the whole, the computational representation of the subsystems of data-driven smart sustainable cities enables planners, designers, engineers, and managers to reproduce and investigate the behaviors or characteristics of these subsystems using different types of simulations and to make informed decisions according to the generated outcomes. These decisions are associated with optimizing the performance and enhancing the designs of urban systems, i.e., the operating and organizing processes of urban life, with respect to sustainability.

\section{Literature review}

3.1 Cities as quintessential examples of complex systems and wicked problems

Cities are complex systems par excellence, more than the sum of their parts. One of the key foci of resilience studies is the problematic of unpredictability. Evolutionary resilience appears appropriate in the urban context (Davoudi et al., 2012). It denotes the ability of a system, not only to bounce back from events causing a shock through robust behavior, but also to adapt and learn from the past behaviors to surpass the previous state by extending its capacity (Gunderson \& Holling, 2002). Such an evolutionary and adaptive view to resilience emphasizes the characteristics of discontinuous change, chaos and order, nonlinear system behavior, and selforganization (Gunderson \& Holling, 2002). Cities are self-organizing social networks embedded in space. Self-organization, as one of the key dynamical properties of complex systems, denotes the emergence of an unplanned order or organized behavior out of seemingly perceived chaos. Central to self-organization is that the actions of a group of individual constituents of a system are coordinated without centralized planning. Accordingly, self-organization is created and controlled by no one. It results from human actions, not from human designs (Hayek, 1978). Self-Organization in conjunction with nonlinear system behavior might increase a city system's capacity for adapting and learning through complex interactions of the rational behavior of individual "micro" agents to adjust to changes, collectively rendering a "macro" adaptive urban emergence (Manesh \& Tadi, 2011; Rowley, 1994). For what it entails compared to simplification, such emerging complexity is seen as beneficial and useful because it increases functional capacity through properties such as hierarchy, flexibility, redundancy, and specialization of different parts, as well as synergy, where the entirety is greater than the sum of the parts.

Emergence, as a dynamical property of complex systems, denotes that larger entities arise through interactions among and between smaller entities. In this context, it describes urban phenomena that are difficult to forecast or to be fully envisioned from the smaller entities that make up the city. Emergent properties result from the relationships, interactions, or dependencies they form by virtue of being within a system, and are not apparent from its parts in isolation. Therefore, emergent systems have properties that can only be analyzed at a higher level, despite the results being sufficiently determined by the activity of the system's basic constituents. In this sense, they entail a simpler higher order behavior that arises from the underlying complex interactions; similar to society emerging from interactions of people. Such micro-agent interactions and adaptations at the individual networking level continually create new emergence and increase the robustness of the whole system (Alexander, 1965; Bettencourt, 2013). Almost all accounts of emergentism involve a form of irreducibility to the lower level. As an example, an 
urban fabric (e.g., inner city) created by multiple actor layers, incrementally developed with a diversity of building types, scales, and functions, is often seen as having the attributes of a more intense and livelier street lives (Eom \& Cho, 2015; Jacobs, 1961; Merlino, 2011). Overall, the evolutionary resilience approach to urban planning seems to deliver the characteristic features of data-driven smart sustainable cities with respect to the compact, ecological, and technological dimensions of their landscape. This is achieved through such system properties as multi-functionality, redundancy and modularization, biodiversity and social diversity, multi-scale networks and connectivity, and adaptable planning (Ahern, 2011). In the context of the compact city, for example, the resilient urban properties that relate to increased diversity, networks, and increased number of agents through density and proximity are often seen in emergent urban areas that have developed incrementally through time (Marshall, 2012; Scheurer, 2007). Some earlier attempts have been made to emulate compact city characteristics in postmodern contexts, i.e., diversity of functions and density. They have typically been undertaken to shape emergent urban forms through site specific designs (Marshall, 2012; Neuman, 2005). However, there is a difficulty in planning the kind of urban complexities that are seen in traditional emergent urban forms through interventions and organizations (Marshall, 2012).

However, Bibri (2018c) provides a detailed account and discussion of the other key dynamical properties of smart sustainable cities as complex systems. This account is an integral part of a systematic exploration of the key structures, behavioral patterns, relationships, interactions, and dependencies underlying smart sustainable cities. This exploration is based on complexity science and systems thinking as theoretic approaches. Homer-Dixon (2011) offers a survey of some core concepts and ideas of complexity science and makes a strong case that they can help us develop new strategies for generating alternative solutions and prospering in this world.

The problems that we deal with in cities fall under what is called in policy analysis "wicked problems" (Rittel and Webber (1973), a term that has gained more currency since the adoption of sustainability within urban planning in the early 1990s. In order to describe a wicked problem in sufficient detail, one has, as stated by Rittel and Webber (1973), "to develop an exhaustive inventory of all conceivable solutions ahead of time. The reason is that every question asking for additional information depends upon the understanding of the problem-and its resolution-at that time ... Therefore, in order to anticipate all questions (... all information required for resolution ahead of time), knowledge of all conceivable solutions is required." Rittel and Webber (1973) argue that the essential character of wicked problems is that they cannot be solved in practice by a central or public planner, who t has no right to be wrong (i.e., planners are liable for the consequences of the actions they generate). Wicked problems are so complex and dependent on so many intertwined factors that it is hard to grasp what they exactly are and thus how to tackle them. In other words, they are difficult to explain and impossible to solve because of incomplete, contradictory, and changing requirements that are not easy to recognize. As a consequence, when tackling wicked problems, they become worse due to the unforeseen consequences and unanticipated effects that were overlooked because the system under study was treated in too immediate and simplistic terms, or as a result of failing to approach it from a holistic perspective.

\subsection{Related work}

Computational and scientific approaches, especially those enabled by big data science and analytics, have become necessary for dealing with the complexities of sustainable cities. Consequently, it is of paramount importance to develop and employ sophisticated methods and innovative solutions for tackling the problems and challenges pertaining to sustainable cities in terms of planning in the face of urbanization. This requires a blend of scientific and academic disciplines, and big data technologies are well placed to initiate this endeavor. Bibri (2021c) provides a detailed account of the scientific and academic disciplines underlying datadriven smart sustainable urbanism, as well as a framework illustrating their integration and fusion from an interdisciplinary and transdisciplinary perspective.

There currently is much enthusiasm about the possibilities created by new and more extensive sources of data to better understand, plan, and govern cities thanks to the IoT and big data analytics. Batty (2013) describes how the explosion of big data is shifting the emphasis from longer term strategic planning to short-term thinking about how cities function and can be managed, drastically altering the way we conceive of, understand, and plan smart cities. In his article 'The Real-time City? Big Data and Smart Urbanism' Kitchin (2014) details how cities as being instrumented with digital devices and infrastructure produce big data that allow real-time analysis of city life, new modes of urban governance, and provide the raw material for envisioning and enacting more efficient, productive, open, and transparent cities. Bibri (2019b) explores the value of big data science and analytics and its uses in dealing with the complexities of sustainable urbanism in terms of wicked problems. The author argues that the upcoming advancements in big data science and analytics, coupled with the ever- 
increasing deluge of urban data, hold great potential to enhance and advance sustainable urbanism. From a computational perspective, Bettencourt (2014) explores how big data can be useful in urban planning by formalizing the planning process as a general computational problem. The author demonstrates that new sources of data coordinated with urban policy under general conditions can be applied following the fundamental principles of engineering and applied sciences to achieve new or more effective solutions to urban wicked problems, and that, regardless of the amounts of data available, a comprehensive form of urban planning remains computationally intractable in large cities.

With reference to smart cities, Rathore, Ahmad, Paul, and Rho (2016) propose an integrated IoT-based system for smart city development and urban planning using big data analytics. Their system consists of various types of sensor deployment, including smart home, vehicular networking, weather and water, smart parking, and surveillance. The authors propose a four-tier architecture: 1) IoT sources and data generation and collection, 2) communication, 3) data management and processing, and 4) application and usage of the data analysis and the results generated. The proposed architecture is implemented using Hadoop with Spark, voltDB, or Storm for real time processing of the IoT data to generate results to establish the smart city. The results demonstrate that the proposed system is more efficient than existing systems, a metric that can be measured in terms of throughput and processing time. In their article "Urban Planning and Smart City Decision Management Empowered by Real-Time Data Processing Using Big Data Analytics," Silva et al. (2018) propose a big data analyticsembedded experimental architecture for smart cities in response to the issue of real-time processing requirements and exponential data growth in relation to their realization. The proposed architecture serves to facilitate exploitation of urban big data in planning, designing, and maintaining smart cities, and also to occupy big data analytics to manage and process voluminous urban big data to enhance the quality of urban services. Three tiers of the proposed architecture are liable for data aggregation, real-time data management, and service provisioning. In addition, offline and online data processing tasks are expedited by integrating data normalizing and data filtering techniques. The authors claim the applicability and reliability of implementing the proposed architecture in the real world.

In connection with data-driven smart sustainable cities, Bibri and Krogstie (2018) propose, illustrate, and discuss a systematic framework for data-driven urban analytics in relation to sustainable urbanism based on cross-industry standard process for data mining. The intention is to utilize and apply well-informed, knowledge-driven decision-making processes to optimize and enhance the operations, functions, services, designs, strategies, and policies of smart sustainable cities in line with the long-term goals of sustainability. Accordingly, one of the uses of such framework pertains to planning and decision process through simulations and decision support. The authors argue that there is tremendous potential to transform and advance the knowledge of smart sustainable urbanism through the creation of a data deluge that can provide much more sophisticated, finer-grained, wider-scale, real-time understanding and control of the various aspects of urbanity.

Many topical studies have addressed a number of areas of environmental sustainability in relation to urban planning or future urban development. With reference to smart eco-cities, Shahrokni et al. (2014b) identify the inefficiency of waste management and transportation using big data analytics and GIS, and suggest potential improvements. As an outcome of an extensive data curation process, the authors develop a series of new waste generation maps based on a large data set consisting of half a million entries of waste fractions, weights, and locations. These maps serve to describe what waste fraction comes from where and the way it is collected. Moreover, the authors analyze the route efficiency and construct the maps of selected vehicle routes in detail, as well as assess the efficiencies of the routes using the efficiency index $(\mathrm{kg}$ waste $/ \mathrm{km})$. They conclude that substantial inefficiencies were revealed, and a shared waste collection vehicle fleet is suggested among other intervention measures to increase the efficiency of waste management. Within the framework of smart cities, Ameer and Shah (2018) propose an architecture for smart urban planning based on Apache Spark data-processing platform, which makes use of big data analytics in classifying the air quality. The authors state that the proposed architecture fullfils the requirements for analyzing and monitoring the large amounts of data generated by the IoT devices. And that it is implemented on the data set of vehicles pollution. The results show that the proposed architecture is efficient and accurate for analyzing and classifying the Air Quality Index (AQI).

In the context of smart eco-cities, Pasichnyi, Levihn, et al. (2019) present a novel data-driven smart approach to strategic planning of building energy retrofitting, using data about actual building heat energy consumption, energy performance certificates (EPCs), and reference databases. This approach allows a holistic city-level analysis of retrofitting strategies thanks to the aggregated projections of the energy performance of each building, such as energy saving, emissions reduction, and required social investment. The case investigated demonstrates the potential of rich urban energy datasets and data science 
techniques for better decision making and strategic planning. The proposed approach allows the change in total energy demand from large-scale retrofitting to be assessed, and explores its impact on the supply side, thereby enabling more precisely targeted and better coordinated energy efficiency programs. In addition, Pasichnyi, Wallin, et al. (2019) review the existing applications of the data of EPCs and propose a new method for assessing their quality using data analytics. The authors identify 13 application domains from a systematic mapping of the analyzed material, revealing increases in the number and complexity of studies as well as advances in applied data analytics techniques. They conclude that EPC data have wider applications than what the EPCs policy instrument was originally designed for, placing stronger requirements on the quality and content of the data. Prior to these two related studies, Shahrokni, Levihn, and Brandt (2014) evaluated the energy efficiency potential of different building vintages in the City of Stockholm in collaboration with the district heating and electricity utility Fortum. The authors found that the retrofitting potential of the building stock to current building codes can reduce heating energy use by $1 / 3$. De Rubeis et al. (2020) use data-driven approaches to daylighting assessment as an alternative to climate-based simulation tools. In their work, they propose a novel method for optimizing energy use and luminous environment for a set of lighting control system solutions. The climate-based simulation results provide the data necessary for the data-driven static optimal control that allows different control strategies of the lighting systems according to the lighting power density. The results show that the method allows to achieve energy savings up to $18.6 \%$ by maintaining high visual comfort levels.

To sum up, sustainable cities are making substantial efforts towards enhancing their sustainability performance and meeting their sustainability commitments by utilizing the IoT and big data analytics in urban development planning. They are increasingly relying on the applied technology solutions offered by smart cities in their endeavor to become data-driven smart sustainable. However, they still tend to focus largely on the environmental dimension of sustainability. Hence, they need to balance the three dimensions of sustainability as they evolve and take advantage of new advances in urban computing and intelligence.

\section{Research methodology}

As mentioned earlier, this study expands on prior work done to develop a novel model for data-driven smart sustainable cities of the future in the form of a strategic planning process of transformative change towards sustainability. The three main phases of this process-(1) the constructed future vision, (2) the specified objectives and targets related to sustainability, and (3) the developed strategies and pathways for transformative change-are grounded in case study research. This was carried out on a total of six of the ecologically and technologically leading cities in Europe. The case study approach, which is associated with the empirical phase of the futures study, was adopted to examine and compare two cases with respect to each of the phenomena of compact cities, smart eco-cities, data-driven smart cities, and environmentally data-driven smart sustainable cities. Bibri (2020b) dedicates a whole article to the methodological framework applied in the futures study, which combines a set of principles underlying several normative backcasting approaches as well as descriptive case study design. The latter is what this paper is concerned with in terms of empirically informing the analysis of the strategic and innovative planning approaches associated with the development and design of data-driven smart sustainable cities of the future.

The case study is a descriptive qualitative approach that is used as a tool to study specific characteristics of a complex phenomenon. The descriptive case study approach, as defined by Yin $(2014,2017)$, was identified as the most suitable approach for the empirical basis of the futures study. In this context, it involves the description, analysis, and interpretation of the four phenomena of urbanism, with a particular focus on the prevailing conditions pertaining to plans, projects, and achievements. That is, how the six cities selected behave as to what has been realized, the ongoing implementation of plans, and the execution of projects based on the corresponding practices and strategies for sustainable development and technological development. To obtain a detailed form of knowledge in this regard, a five-step process tailored to each of the four case studies was adopted (Table 1).

The four case studies investigated contemporary realworld phenomena with the objective to inform the theory and practice of data-driven smart sustainable urbanism by illustrating what has worked well, what needs to be improved, and how this can be done in the era of big data and in the face of urbanization. They were particularly useful for understanding how different elements fit together and (co-)produce the observed impacts in a particular urban context based on a set of intertwined factors. Overall, the four case studies conducted were useful for illuminating the four urban phenomena, for illustrating the general principles underlying these phenomena, and for generating new ideas and research questions involving the relationships between these phenomena. However, the case studies cannot substitute for carefully controlled correlational studies as they by definition are low in internal validity and external validity. These two concepts reflect whether or not the results of the four case studies are trustworthy and meaningful. 
Table 1 A five-step process tailored to the four case studies conducted

\section{Compact Cities}

- Using a narrative framework that focuses on the compact city model and its contribution to the three goals of sustainability as a real-world problem and that provides essential facts about it, including relevant background information

- Introducing the reader to key concepts, strategies, practices, and policies relevant to the problem under investigation

- Discussing benefits, conflicts, and contentions relevant to the problem under investigation

- Explaining the actual solutions in terms of plans, the processes of implementing them, and the expected outcomes.

- Offering an analysis and evaluation of the chosen solutions and related issues, including strengths, weaknesses, tradeoffs, and lessons learned.

\section{Eco-Cities}

- Using a narrative framework that focuses on the eco-city as a real-world problem and provides essential facts about it, including relevant background information

- Introducing the reader to key concepts, models, and design strategies relevant to the problem under investigation

- Discussing benefits and research gaps and issues relevant to the problem under investigation

- Explaining the actual solutions in terms of plans, the processes of implementing them, and the expected outcomes

- Offering an analysis and evaluation of the chosen solutions and related issues, including strengths, weaknesses, tradeoffs, and lessons learned.

\section{Data-Driven Smart Cities}

- Using a narrative framework that focuses on the data-driven smart city as a real-world problem and provides essential facts about it, including relevant background information

- Introducing the reader to key concepts, technologies, and data-driven smart sustainable urbanism processes and practices relevant to the problem under investigation

- Providing an overview of the literature review previously conducted in relation to the study, which delivers a comprehensive, state-of-the-art review on the sustainability and unsustainability of smart cities in relation to big data technologies, analytics, and application in terms of the underlying foundations and assumptions, research problems and debates, opportunities and benefits, technological developments, emerging trends, future practices, and challenges and open issues

- Explaining the actual solutions in terms of plans, the processes of implementing them, and the expected outcomes

- Offering an analysis and evaluation of the chosen solutions and related issues, including strengths, weaknesses, tradeoffs, and lessons learned.

\section{Environmentally Data-Driven Smart Sustainable Cities}

- Using a narrative framework that focuses on data-driven smart solutions and their role and potential in improving and advancing environmental sustainability in the framework of the smart sustainable city as a real-world problem, and provides essential facts about it, including relevant background information.

- Introducing the reader to key concepts, core enabling technologies, infrastructures, landscapes, frameworks, as well as urban operating systems and urban operations centers, all with relevance to the problem under study.

- Identifying the commonalities and differences between the two cities with respect to the emerging technologies

- Explaining the actual solutions in terms of plans and visions, the processes of implementing them, and the realized and expected outcomes

- Offering an analysis and evaluation of the relevant solutions and related issues, including strengths, weaknesses, and lessons learned.

Internal validity relates to how well these studies are conducted in terms of their structure, whereas external validity pertains to how well the outcomes of these studies are applicable to the real world. Generally, internal validity denotes the approximate truth about inferences regarding cause-effect, or the extent to which a reliable causal relationship between a treatment and an outcome can be established in a study. The descriptive research design was used to describe some characteristics of complex urban phenomena, and did not address questions about why these characteristics occurred-no causal relationship. As regards external validity, it is concerned with whether the results of a study can be generalized to and across other settings. A common limit of case studies is that they do not lend themselves to generalizability.
Typical risks include the representativeness of the subjects with respect to the target population in terms of sustainable cities and smart cities.

\section{Results}

The focus of the results in this study is on the strategic and innovative planning approaches that should be considered in the development and design of data-driven smart sustainable cities of the future. This new model of urbanism itself represents a strategic planning process of transformative change towards sustainability based on backcasting. The planning approaches identified, analyzed, and discussed in this study are intended to support the process of backcasting, thereby expanding on the following studies: 
Bibri and Krogstie (2020d) distill and enumerate the underlying components of the new model of urbanism in terms of its dimensions, strategies, and solutions based on the overall outcome of case study research. The authors subsequently combine and integrate these components into an applied theoretical framework for strategic sustainable urban development planning. The argument underlying this integrated framework is that the IoT and big data technologies and their novel applications offered by smart cities of the future have great potential to enhance and consolidate the design strategies and environmental technology solutions of sustainable cities This results in improving and advancing the contribution of sustainable cities to the environmental, economic, and social goals of sustainability through harnessing its synergistic effects and balancing its dimensions. However, the proposed framework is used to guide the development of the novel model for datadriven smart sustainable cities of the future as a strategic roadmap towards transformational change in the era of big data. This is the aim of the study carried out by Bibri and Krogstie (2021), where the authors identify a set of actions and measures in the form of strategic pathways to transform the built infrastructure, sustainable urban infrastructure, smart urban infrastructure, social infrastructure, and technological infrastructure of the landscape of data-driven smart sustainable cities of the future. The essence of this aggregate model lies in providing the needed tools, techniques, methods, systems, platforms, and infrastructures enabled by the core enabling and driving technologies of the IoT and big data analytics for sustainable cities to have a more measurable, targeted, and harmonized contribution to sustainability. This in turn means finding and applying more effective ways of translating sustainability into the physical, spatial, environmental, economic, and social forms of sustainable cities with regard to planning and design. This is what this study mainly contributes with through substantiating the potential role of urban computing and intelligence in this regard. The strategic planning approaches related to compact cities and eco-cities are particularly associated with the built infrastructure of datadriven smart sustainable cities of the future, whereas the innovative planning approaches are associated with all of the five infrastructures underlying their landscape.

\subsection{Strategic sustainable planning}

\subsubsection{Planning approaches, planning types, and urban fabrics and their relationship}

The built infrastructure as one of the core dimensions of the landscape of data-driven smart sustainable cities of the future is largely associated with the core design strategies of the compact city and the eco-city. It denotes the patterns of the physical objects related to the built-up areas as well as those areas planned for new development and redevelopment together with related essential urban infrastructure. The compact and ecological dimensions of urban design chacterize most of the built infrastructure as regards its buildings, blocks, streets, open space, public space, and green space.

To stage an expansion of the built environment involves three strategic planning approaches (Table 2), which represent the outcomes of three planning types: planning by design, planning by development control, and planning by coding (Table 3 ).

With the combination of these three planning types, which can promote urban complexity, the built infrastructure of data-driven smart sustainable cities should develop sustainably in terms of compactness as well as greening, sustainable buildings, and sustainable materials, in accordance with the five expansion strategies

Table 2 Strategic planning approaches and related planning types

\section{Strategic Planning Approaches \\ Emergent compact urban form: An inner city urban fabric evolved} through time by multiple actors' interactions

Designed dispersed urban form: A modernist urban fabric at a given point of history where the system of ideas and ideals, which forms the basis of policy, was to separate and create separation between the functions and to give uniform characteristics and standards

Designed compact urban form: An inner city urban fabric where density and diversity have been designed by a number of developers simultaneously.

\section{Planning Types}

Emergent compact urban form represents the outcome of planning by coding, which is aimed at high density and diversity facilitates incremental and individual micro interactions through time and space by multiple actors. As urban systems, they have the possibilities to change and adapt to create new emerged states since emergence is continuous and diversity is high.

Designed dispersed urban form represents the outcome of planning by design, where rationalization and simplification create compartmentalized urban patterns. These plans, which are typical for modernistic and topdown planned urban systems, are often executed through large-scale site interventions with long-term projections into the future.

Designed compact urban form represents the outcome of planning by design - usually in combination with planning by development control, which are often applied in new initiatives to emulate emergent compact urban form characteristics. They are initiated top-down and focus on functional diversity, density, as well as the diversity of property ownership and housing tenure. 
Table 3 Three planning Types

\begin{tabular}{ll}
\hline Planning Types & Descriptions \\
\hline Planning by design & $\begin{array}{l}\text { Master planning, urban design, or outlines of design, with a preconceived conception of the finished state of a specific } \\
\text { whole entity. }\end{array}$ \\
$\begin{array}{l}\text { Planning by coding } \\
\text { be generative with specifications to how elements can be combined to produce an aggregate urban form. A generative } \\
\text { code provides a framework within which individual designers can work. }\end{array}$ \\
$\begin{array}{l}\text { Planning by development } \\
\text { control }\end{array}$ & $\begin{array}{l}\text { Enabling public authorities' influences on what is allowed to be built or not by approving or rejecting specific designs } \\
\text { or layouts proposed by private individuals and developers or master planners. }\end{array}$
\end{tabular}

Source: Marshall (2012)

(Table 4). These relate to the intensification strategy of compactness, which encompasses a number of processes for the renewal, infill, development, and redevelopment of urban areas, notably:

- Increase the population of the city.

- Increase the redevelopment of previously developed sites, subdivisions and conversions, and additions and extensions.

- Increase the development of previously undeveloped or less developed sites.

- Increase the density and diversity of sub-centers.

- Invest in and improve transport infrastructure and services.

- Protect and integrate large natural and cultural areas.

These are to be applied to the six urban fabrics identified based on the investigated cases of compact cities (Bibri et al., 2020) and eco-cities (Bibri \& Krogstie, 2020a). An urban fabric denotes the physical characteristics of urban areas in terms of components, materials, buildings, spatial patterns, scales, streetscapes, infrastructure, networks, and functions, as well as socio-cultural, ecological, economic, and organizational structures.

The three strategic planning approaches should deliver the desired outcomes with respect to sustainable urban design within the framework of data-driven smart sustainable cities of the future. The mix of the three planning types is of criticality as to capacitating planning to accommodate such parameter as timing, building density and scale distribution, diversity, mixed land use, passive and low-carbon buildings, green space distribution, and decentralization of planning and design activities to multiple actors. The outcomes of the three planning typessix urban fabrics-serve to understand how planning in its various combined forms influence and shape the development of data-driven smart sustainable cities of the future in terms of compact and ecological design. The challenge is to design it in a way that creates the desired functional complexity (Batty \& Marshall, 2012). When

Table 4 Six urban fabrics and related strategic planning approaches

\begin{tabular}{|c|c|}
\hline Expansion Strategies & Urban Fabrics and Related Strategic Planning Approaches \\
\hline Build and develop centrally & $\begin{array}{l}\text { The central renewal area relates to the emergent compact urban form approach, which has evolved incrementally } \\
\text { by multiple actors through time and space. } \\
\text { The inner city is associated with the designed compact urban form approach, mainly diversity-oriented to emulate } \\
\text { emergent characteristics. It also involves the designed dispersed urban form approach, reductionist and top-down. }\end{array}$ \\
\hline Concentrate on strategic nodes & $\begin{array}{l}\text { The prioritized development areas have to do with the designed compact urban form approach, density and } \\
\text { diversity-oriented to emulate emergent characteristics. }\end{array}$ \\
\hline Complement and mix & $\begin{array}{l}\text { The concerned areas to be supplemented are associated with the designed compact urban form approach, } \\
\text { density and diversity-oriented to emulate emergent characteristics. They also involve the designed dispersed } \\
\text { urban form approach, reductionist and top-down. The first approach concerns the new urban intensification pro- } \\
\text { jects that are to be developed by the municipality, as well as the construction of a mixture of housing in terms of } \\
\text { forms and tenure types. The second approach pertains to programs and projects for solving social and socio- } \\
\text { economic issues. }\end{array}$ \\
\hline $\begin{array}{l}\text { Reserve outer areas for future } \\
\text { consideration }\end{array}$ & $\begin{array}{l}\text { The outer area, which is yet or about to be developed, should be strategically planned based on the designed } \\
\text { compact urban form approach from the outset. This is driven by the core design strategies of the compact city in } \\
\text { terms of density, diversity, mixed land use, sustainable transportation, green space, as well as the design features } \\
\text { of the eco-city. }\end{array}$ \\
\hline Develop new districts & $\begin{array}{l}\text { The new districts should be based on the integration of the design strategies of the compact city and eco-city } \\
\text { models as planning systems, supported with new technologies as regards to monitoring and analyzing urban } \\
\text { areas and green conditions. }\end{array}$ \\
\hline
\end{tabular}


combined into a system of planning, the three types of planning can promote urban complexity (Marshall, 2012).

\subsubsection{The role of big data uses in strategic sustainable planning}

The urban fabrics identified as part of the built infrastructure of data-driven smart sustainable cities of the future should be-as urban complexities-monitored, understood, analyzed, and continuously planned using big data technologies to achieve the desired outcomes of sustainability, particularly in relation to the compact and ecological design features of the built environment. One of the applications of big data technologies in strategic sustainable planning relates to land use and infrastructure in terms of the analysis of population data and the evaluation of the potential impacts of urban growth. This allows sustainable cities to take into account emerging demands from citizens for certain venues and to prioritize initiatives and allocate resources appropriately. The data-driven smart approach to strategic planning enables the development of new districts, streets, buildings, green areas, facilities, public spaces, public transport routes, distribution wires on poles or underground, waste sorting stations, and road infrastructures based on the information collected on human mobility, physical movement, intensive activity, and residents' expectations. In addition, sustainable cities can benefit from integrating the data regarding the various uses of urban areas to build scenarios in response to the need for urban revitalization, renewal, and redevelopment. This makes it possible to improve the way urban areas meet the needs of the residents, to share environmental and social practices, to enhance participation and consultation, and to engage in dialogue with the residents. The focus should be on revitalizing inner-city neighborhoods through initiatives aimed at reorganizing existing structures in neighborhoods in decline in response to social and economic or socio-economic issues. Also, by building in favor of cycling and walking in response to the needs of residents, car traffic can be reduced in the city centers, leading to better health among the residents. Likewise, developing green areas as part of strategic nodes can help create meeting places and also play the role of air cleaners, water collectors, and noise reducers, in addition to providing ecosystem services.

In addition, the data-driven smart approach to strategic planning plays a role in building energy retrofitting based on sustainable design and green and efficient technologies, using data about actual building energy consumption, local energy production potential, energy performance, and so on. The value of such approach lies in enabling a holistic city-level analysis of retrofitting strategies, owing to the aggregated projections of the energy performance of buildings. Limiting pollution levels requires a substantial decrease in the average carbon intensity of buildings in relation to different urban fabrics. This in turn requires using advanced decision-support systems that enable large scale energy efficiency improvements in the existing building stock. One of the common hurdles preventing the widespread adoption of energy efficiency measures in buildings is the poor design of buildings, which makes it difficult to implement Building Management System (BMS) and to apply common standards for efficiency and operation. The most effective approach to overcome this hurdle and thus realize the full potential of data-driven technologies is to design innovative policies, policy-enable practices and practice informed policies based on big data analytics.

Furthermore, the social fabric of data-driven smart sustainable cities is the result of many intertwined, multi-faceted networks of relations between places, people, institutions, activities, and mobilities. It is important to understand the structure of these coupled networks, and how it evolves. The recent research in social networks driven by big data technologies has started to focus on the extent to which individual mobility patterns shape and impact social networks as well as transport behavior and the psychology behind it (Bibri, 2018c). This is associated with the design strategies of sustainable cities in terms of compactness, density, mixed-land use, diversity, and sustainable transportation.

\subsection{Innovative planning approaches enabled by data- driven smart technologies}

5.2.1 Short-term planning: real-time data aggregation and continuous reflection

The planning system of data-driven smart sustainable cities of the future should be based on-maximizing the use of data to guide their development and design and encouraging developers to adopt a more consistent approach to deploying digital infrastructure to future proof new developments. This paradigm of urbanism is associated with the kind of challenges that are enormous enough to call for novel approaches to planning. This is due to several factors, coupled with the ability of emerging simulation models to address some of the new conceptions of how data-driven smart sustainable cities function as complex systems. These are distilled and implied from the strategies and solutions identified based on the three case studies conducted on data-driven smart cities, environmentally data-driven smart sustainable cities, and smart eco-cities in a series of bullet points: 
- Smart cities and sustainable cities are being, though to varying degrees, transformed from places dominated by physical actions to places in which such actions are complemented by the use of datadriven technologies.

- The physical landscape of sustainable cities is being merged with the digital landscape of smart cities, resulting in computationally augmented urban environments thanks to the hybrid systems bridging the physical and digital world enabled by urban computing and intelligence.

- Computer control is ushering in nearly all routine functions of smart cities and gradually evolving in this direction within sustainable cities.

- The number of important urban operations that can be performed without thinking about them is being extended, using various forms of automation in smart cities and gradually in sustainable cities.

- The provision of data from the functions of smart cities and sustainable cities is offering the opportunity of a city in which the effects of how it is functioning is continuously available thanks to real time data and time-scale compression. Still, smart cities differ from sustainable cities in regard to the areas of focus in this regard.

- The availability of real-time data from the operations and functions of smart cities and sustainable cities is offering the opportunity to continuously provide their synoptic intelligence. This provides insights into how they are performing as regards their targets at different spatial scales and over different temporal scales.

- The emergence of real-time data from the bottom up is causing space scales and time scales to collapse. In this respect, datasets are becoming able to show the real-time functioning of smart cities and sustainable cities, and also to imply how long-term changes can be detected and dealt with at different spatial scales and over different time scales thanks to the aggregation of real-time data.

- The aggregation of real-time data to deal with changes in smart cities and sustainable cities is making it possible to advance the models that we are able to build and apply and the way in which these data-driven technologies can inform the planning and decision process with simulations and decision support conflated across space and time.

- The use of advanced simulation models is further enabling simulating various activities in smart cities and sustainable cities that will evolve as their structures themselves evolve and become smarter. This pertains to urban dynamics as self-organizing evolution processes in terms of the forces or properties that stimulate growth, development, or change within the city system.

- The evolving models of smart cities and sustainable cities functioning in real-time and the ability of urban ubiquitous sensing to provide information about longer term changes is giving rise to a sense of urgency for the construction of new forms of simulation models that inform future designs and address the current conceptions of urban complexities. In this regard, many different kinds of models are being explored building on and extending the scope of the sciences underlying data-driven smart sustainable urbanism.

- The use of big data analytics is enabling identifying the macroscopic observables and control parameters that influence individual decisions in smart cities and sustainable cities, and then integrating them in agent-based simulation models based on the large number and variety of trajectories of citizens in different locations.

- The use of human mobility data is opening up opportunities for more effective analysis and deep understanding of the relationship between individual and collective mobility and the environmental, economic, and social effects that are presumed to be produced by the design strategies of sustainable cities.

- The use of big data analytics is allowing to predict socio-economic, environmental, and demographic changes and to devise novel solutions for integrating and consolidating the design strategies of sustainable cities and mitigating the fragmentation of their designs and environmental technologies.

- The use of big data analytics is making it possible to devise new theories of how data-driven smart sustainable cities function in ways that focus on much shorter term issues of sustainability than hitherto, as well as on much more on human mobility and physical movement than long-term urban functioning in regard to sustainable development.

The ever-increasing deluge of urban data epitomizes a sea change in the kind of data that can be generated about urban systems and environments as regards what happens and might happen where, when, why, and how so as to devise more effective actions and measures for enhancing the planning and design of data-driven smart sustainable cities of the future. It has become possible to assess what is happening at any one time and to react and plan appropriately, instead of basing decisions on periodic or partial evidence. Big data analytics is bringing about major transformations in understanding and redefining the problems and issues of sustainability in new and innovative ways for more effective planning 
and efficient design. In particular, it is pushing planning into short termism as regards how emerging data-driven smart sustainable cities function and can be managed, which adds a whole new dimension to urban sustainability by shifting away from long-term strategic planning. Short-termism in planning is about measuring, evaluating, modelling, and simulating what takes place in the city over hours, days, weeks, or months instead of years, decades, or generations, and creating a set of actions and measures to improve performance with respect to the various areas of sustainability. Indeed, urban analysts are often expected to produce answers in such a short time; work by exploratory analysis and rapid iteration based on processes with well-defined stages; and produce and present results by displaying them in an understandable format for human interpretation. The results can then be deployed for decision-making or problem solving purposes (e.g., improving, adjusting, or changing an operation, a function, a service, a design, a strategy, or a policy).

Speaking of these urban processes and practices, urban computing and intelligence can create feedback loops between humans and their activities and the urban environment, to reiterate. Feedback control theory provides the framework for the development and optimization of any data-driven smart solution. The concept of feedback loops, one of the key dynamical properties of complex systems, refers to a system where part of its output is used for new input in the sense that the latter can be increased or decreased depending on the outcome of the former. Feedback loops are either positive or negative (reinforcing or balancing) in nature. With respect to the former, they tend to enhance or amplify changes, which tends to move a system away from its equilibrium state and make it more unstable. This occurs when a disturbance is accentuated. Concerning the latter, they tend to dampen or buffer changes, which tends to hold a system to some equilibrium state, making it more stable, i.e., changes are detected and reversed. A feedback loop is a powerful mechanism when it comes to designing control systems related to the technological and engineered systems related to the operating and organizing processes of urban life. In this regard, feedback as valuable information can be used to make important decisions in the context of data-driven smart sustainable cities of the future as to improving and maintaining their performance with respect to their administration spheres (energy, transport, traffic, mobility, environment, waste, urban metabolism, healthcare, etc.) based on analytical engineering solutions. This involves enhancing and optimizing the operations, functions, services, strategies, and policies pertaining to these domains. For example, practicepolicy feedback loops ensure that barriers to effective practice concerning environmental sustainability are brought to the attention of policy makers, and assist in the development of policy enable practices and practice informed policies based on the analytical outcome of the collected data. As another example, using real-time data in the analysis of the flows of the energy and materials in urban environment and their relationship with urban infrastructure and activities enables a new understanding of the causalities that govern urbanism, and allows city stakeholders to receive feedback on the system consequences of their choices and actions, with the objective to devise measures or strategies for optimization. These can be operated intuitively by humans but can also be implemented automatically using advanced algorithms with access to the necessary measurements and actions.

Further, feedback information can be automatically extracted from large masses of urban data through data mining or knowledge discovery processes. It is thus intended to enhance decision-making pertaining to the operational functioning of urban systems as a set of interrelated procedures, mechanisms, and measures. These can be planned, implemented, assessed, and improved in a continuous way based on the output of a given system with respect to its performance. Data-driven technologies are offering radically novel solutions to difficult problems. Solutions sometimes need speed instead of smartness, Indeed, under specific conditions, the simple solutions requiring no great intelligence can solve difficult problems, which has a lot to do with the extent to which the measurement and adequate simple reactions are fast and precise (Bettencourt, 2014). This is the logic of feedback control theory as part of modern engineering (Astrom \& Murray, 2008). Therefore, knowing the desired operating point for a system and having the means to operate on the system while observing its state change via feedback loops can enable us to turn it into a simple problem under the general, crucial conditions that can measure and recognize potential problems just as they start to arise and act to make the necessary corrections (Bettencourt, 2014). In this regard, the important issue is the temporal scales in that every system (transport, traffic, mobility, energy, waste, environment, street lighting, parking, healthcare, etc.) has intrinsic timescales at which problems develop-seconds, minutes, hours, days, and so on. The enabling and driving technologies underpinning urban computing and intelligence are increasingly so fast that myriads of key policy problems related to environmental and social sustainability are falling within this window of opportunity. Models of system response enabled by data-driven technologies can be very simple and crude. The analytical engineering approach bypasses the complexity that can arises in the nested systems of data-driven smart sustainable cities in terms of their operation at longer temporal or larger spatial scales. Many examples of city 
development planning and operational management that use data more effectively fall within this category, regardless of being implemented by humans or by algorithms.

\subsubsection{Joined-up planning: coordination and integration for enhancing sustainability performance}

Within the framework of data-driven smart sustainable cities of the future, planning is to be exercised at different spatial scales (both institutionalized and noninstitutionalized entities), and also as a function of many diverse stakeholder groups. Planning includes privatesector participation in public-private partnerships. This requires what is called joined-up planning, which relates to the kind of connectivity, networking, system interoperability, database integration, and data aggregation enabled by ICT of ubiquitous computing. This is essentially network-based and enables an extensive interaction across many spatial scales and urban domains. At the core of the process of integration and coordination using state-of-the-art data systems, distributed computing, and cooperative communication involves ways in which planners, developers, experts, professionals, and citizens are able to exchange knowledge and blend it together for some purposes, ways of improving the different aspects of sustainability. Joined-up planning is a form of integration and coordination that enables the city-wide effects of environmental, economic, and social sustainability to be tracked, understood, analyzed, and built into the very designs and responses characterizing the operations and functions of data-driven smart sustainable cities.

The integration of urban systems, the coordination of urban domains, and the coupling of urban networks as enabled by advanced ICT are key for designing and developing data-driven smart sustainable cities of the future. This is seen as an endeavor that connects up their infrastructures and services so that they can function more effectively and thus perform well with respect to their contribution to the environmental, economic, and social goals of sustainability. Table 5 presents an example of how various systems and domains might connect up in the context of data-driven smart sustainable cities of the future.

Table 5 A typology of data-driven smart sustainable city functions

\begin{tabular}{|c|c|c|}
\hline Smart Sustainable Built Form & Smart Sustainable Citizens & Smart Sustainable Governance \\
\hline $\begin{array}{l}\text { - Compactness } \\
\text { - Density } \\
\text { - Mixed-land use } \\
\text { - Diversity } \\
\text { - Sustainable transportation } \\
\text { - Green and net-zero buildings } \\
\text { - Passive and low-energy houses } \\
\text { - Sustainable and smart materials } \\
\text { - Green and blue infrastructure } \\
\text { - Monitoring of green space condition } \\
\text { and composition }\end{array}$ & $\begin{array}{l}\text { - Cultural enhancement } \\
\text { - Engagement and creativity } \\
\text { - Socio-economic plurality } \\
\text { - Cultural diversity } \\
\text { - Lifelong learning } \\
\text { - Sustainable lifestyles } \\
\text { - Participation and consultation } \\
\text { - Empowered and well-informed citizenry } \\
\text { - Education and training }\end{array}$ & $\begin{array}{l}\text { - New forms of e-government } \\
\text { - New modes of governance } \\
\text { - Coordination of government agencies towards } \\
\text { collaboration and optimization } \\
\text { - Evidence-based decision-making and policy formulation } \\
\text { - Democratic processes } \\
\text { - Transparent, participatory, and accountable government }\end{array}$ \\
\hline Smart Sustainable Mobility & Smart Sustainable Environment & Smart Sustainable Living \\
\hline $\begin{array}{l}\text { - Spatial and non-spatial accessibility } \\
\text { - Need balance between mobility and } \\
\text { accessibility } \\
\text { - Car and bicycle sharing } \\
\text { - Walking and cycling } \\
\text { - Interoperable multi-modal public } \\
\text { transport } \\
\text { - Car pools (biogas and electric) } \\
\text { - Private cars (biogas and electric) }\end{array}$ & $\begin{array}{l}\text { - Environmental quality } \\
\text { - Ecological diversity } \\
\text { - Biodiversity } \\
\text { - Resource efficiency } \\
\text { - Reuse and recycling } \\
\text { - Pollution prevention } \\
\text { - Ecosystems preservation } \\
\text { - Conservation policies } \\
\text { - Environmental justice } \\
\text { - Public involvement stewardship } \\
\text { - Smart environmental monitoring }\end{array}$ & $\begin{array}{l}\text { - Social cohesion } \\
\text { - Social inclusion } \\
\text { - Social interaction } \\
\text { - Social equality } \\
\text { - Cultural facilities } \\
\text { - Public health and safety } \\
\text { - Affordable and good housing } \\
\text { - Quality of utilities } \\
\text { - Public services } \\
\text { - Job opportunities } \\
\text { - Work benefits }\end{array}$ \\
\hline Smart Sustainable Planning & Smart Sustainable Economy & Smart Sustainable Energy \\
\hline $\begin{array}{l}\text { - Strategic planning } \\
\text { - Sustainable planning } \\
\text { - Master planning } \\
\text { - Environmental planning } \\
\text { - Infrastructure planning } \\
\text { - Land-use planning } \\
\text { - Local planning } \\
\text { - Regional planning } \\
\text { - Urban revitalization } \\
\text { - Economic forecasting } \\
\text { - Community economic development }\end{array}$ & $\begin{array}{l}\text { - Business ethics } \\
\text { - Green innovation and investments } \\
\text { - Environmental integration into economic } \\
\text { decision-making } \\
\text { - Data-driven business processes } \\
\text { - Efficiency and cost saving } \\
\text { - Green ICT for economic innovation } \\
\text { - Sustainable production and consumption } \\
\text { - Sharing and open data economy } \\
\text { - Industrial ecology }\end{array}$ & $\begin{array}{l}\text { - Integrated renewable solutions } \\
\text { - Green energy technologies } \\
\text { - Smart grids } \\
\text { - Smart meters } \\
\text { - Smart home monitoring } \\
\text { - Bio-fueled combined heat and power (CHP) system } \\
\text { - Biogas-fuelled public transport system } \\
\text { - Smart urban metabolism }\end{array}$ \\
\hline
\end{tabular}


Data-driven technologies make it possible not only to integrate urban systems and coordinate urban domains, but also to couple urban networks in order to improve land use, focus urban development, optimize resource utilization, reduce operational costs, and streamline urban processes. The integration of urban systems is justified by the need to organize sustainable cities in terms of their operations, functions, services, strategies, and policies for more effective and efficient functioning, management, and planning. Moreover, data-driven technologies can help sustainable cities to quickly identify their underperforming domains, evaluating improvement and cost-saving potentials, and prioritizing domains and actions for performance efficiency interventions using data-based decision-support systems. This involves identifying the inefficiencies of transport system, energy system, waste management system, street lighting system, distribution networks, and so on, and then suggesting potential improvements accordingly.

Urban networks as a form of organization involving place-bound activities and transport networks exist to speed the flow of goods, people, and ideas. They are associated with spatial planning, a set of methods used to influence the distribution of people and activities in spaces of various scales. They can be described as "major nodes or concentrations of activities and physical and/or functional connections between nodes in a geographical area," where "places can also be characterized by the amount and diversity of activities to be accessed by means of a transport network" (Cheng, Bertolini, Le Clercq, \& Kapoen, 2013, p. 1). Ducruet (2020) reviews operational urban networks in relation to spatial planning, as well as empirical analyses of intercity transport and other systems, providing insights into a multilayered approach to urban networks and integrating local socioeconomic determinants.

In view of the above, data-driven smart sustainable cities have the opportunity to be cross-cutting and thus contribute to the three dimensions of sustainability in more synergistic and integrative ways. In this regard, they are about what the people's needs and concerns are and how these can be delivered and responded to through joined-up planning. Big data are the best way of articulating these needs and concerns, and can be used to develop master plans and good designs to improve and advance the contribution of sustainable cities to sustainability. The linking of diverse forms of urban data provides a deeper, more holistic analysis, which makes it possible to control, manage, and regulate urban life on the basis of evidence-based decisions in line with the vision of sustainability. The use of integrated, real-time data analytics provides a powerful means for making sense of, organizing, and living in the city, as well as for creating visions of sustainable futures.
All in all, data-driven smart sustainable cities relate to advanced ICT not only as a tool to enable and enhance urban planning practices across and within institutional entities and citizen communities, but also in terms of its role as a distributed infrastructure of computing recourses, capabilities, and interfaces in facilitating the development and management of urban infrastructures, activities, and services. Therefore, this visionary model of urbanism entails a socio-technical amalgam of institutions and multiple actors, including universities, research institutes, industry consortiums, and policy networks, as well as ICT companies, planning councils, utility companies, and energy cooperatives. In other words, it involves complex socio-technical constellations and configurations of a variety of urban, technological, scientific, social, political, cultural, and institutional actors and factors interacting with and influencing each other on multiple scales and with different levels of intricacy. At the core of this dynamic interplay is the engagement of many stakeholders in continuous dialogue to determine the projects and programs associated with the development and design of data-driven smart sustainable cities of the future. This also is a matter of orchestration of the development, implementation, management, and maintenance of the ICT infrastructure together with the relevant requirements for technical features and multidimensional performance. However, data-driven smart sustainable cities are essentially dependent on the initiative by and interest of their stakeholders-that each sees it as of relevance and meaningfulness enough to play a role in a specific area-and that their initiatives should be coordinated so that they can complement and support one another for the purpose of developing and implementing data-driven technologies and solutions all the way to improve and advance sustainability.

\subsection{Urban intelligence and planning functions}

Joined-up planning is at the core of urban intelligence in the sense of weaving its functions into the fabric of civic institutions whose mandate is improving the health of the city and enhancing the quality of life and well-being for its citizenry. Civic institutions are associated with some of the key issues that data-driven smart sustainable cities should think about in improving the quality of the urban environment (see Bibri, 2021b for further detail). These issues should be taken into account when developing urban intelligence and planning functions for joined-up planning. Moreover, data-driven smart sustainable cities use different types of technologies to collect and analyze data to gain deep insights that can be applied to manage assets, resources, and services efficiently, thereby optimizing and enhancing urban operations. They are depicted as constellations of instruments across many scales that are connected through multiple 
networks (broadband, Wi-Fi network, mobile network, fibre-optic network, etc.) characterized by high speed and (a modicum of) intelligence. These networks provide continuous data regarding the different aspects of urbanity in terms of the flow of decisions about the physical, environmental, economic, and social forms of the city. These decisions are to be supported by what is called urban intelligence and planning functions, which are able to integrate and synthesize urban data to some purpose, ways of improving the functioning and performance of cities. In this context, functional requirements are what the city system is expected to do and the capabilities it needs to have, whereas performance requirements are how well the city system functions with respect to improving sustainability, efficiency, resilience, equity, and life quality.

As illustrated in Fig. 1, urban intelligence and planning functions represent new conceptions of how data-driven smart sustainable cities function and utilize, integrate, and harness complexity science, urban complexity theories, sustainability science, urban sustainability theories, urban science, data science, and data-intensive science in constructing powerful new forms of simulation models and optimization methods that can generate urban forms, urban structures, spatial organizations, and spatial scales. These are intended to improve sustainability, optimize efficiency, enhance equity, and generate a better quality of life.

Data-driven smart sustainable cities need to evolve urban intelligence and planning functions in response to the emerging trend of building models of smart cities and sustainable cities functioning in real time from routinely sensed data. This is coupled with unobtrusive and ubiquitous sensing getting closer to providing quite useful information about longer term changes in cities (see, e.g., Ameer \& Shah, 2018; Bibri \& Krogstie, 2020b, 2020c; Kitchin, 2014; Nikitin, Lantsev, Nugaev, \& Yakovleva, 2016; Rathore et al., 2016; Silva et al., 2018; Sinaeepourfard et al., 2016). Urban intelligence functions are associated with the control, management, optimization, and enhancement of the operating and organizing processes of urban life. As such they involve a number of technologies and competences. Instrumentation and computerization produce large masses of data based on the whole complex of data sources, data routinely generated about the city and its citizens by a range of public and private organizations. These sources include sensors, cameras, transponders, meters, actuators, GPS, and transduction loops monitoring various phenomena, as well as a multitude of smartphone apps and sharing economy platforms generating a range of real-time location, movement and activity data. The data generated are to be transferred to a horizontal information system for further processing and analysis that consists of data infrastructure and operating system. Functionally compatible horizontal information systems allow the creation of a united ecosystem by linking together diverse smart technologies and solutions to coordinate urban systems and domains by means of a number of functions. Overall, the different data analytics components associated with urban intelligence functions include data sources, system components, enabling technologies, functional elements, and analytics types (i.e., descriptive analysis, diagnostic analysis, predictive analysis, prescriptive analysis, and inferential analysis). They are used to gather and manage data on a variety of urban systems and domains, to model urban phenomena, and to provide the necessary simulation and visualisation tools to be integrated into decision support systems.

Urban intelligence labs are intended to work directly with various urban actors (e.g., government agencies, public authorities, organizations, institutions, companies, communities, citizens, etc.) to acquire, process, and analyze data to extract useful knowledge in the form of applied intelligence. Their main objective is to solve tangible and significant problems of urban planning and design through enhanced decision-making processes. This involves delivering the problem-oriented research that advances the scientific understanding of the city with respect to sustainability and urbanization and how they intertwine with and influence each other, and that directly reshapes and impacts decision-making in the sense of enhancing urban planning and design practices and solving urban problems. With the projected advancements and innovations in urban computing and big data analytics, the process of developing urban intelligence functions will shift from top-down (expert and professional organizations) to engaging citizens with experts in response to the problematicity surrounding the planning of data-driven smart sustainable cities. This entails integrating databases and models from across various urban domains in order to support the development of this sort of integrated intelligence functions, with new or refashioned ways at different levels, including the visualization of data and sustainability problems, the use of tools for informing and predicting the impacts of future sustainability scenarios, and the involvement of citizens and their relevant recommendations, all into a form of a holistic system that operates at different spatial scales and over different temporal scales.

The sort of urban intelligence and planning functions envisaged for data-driven smart sustainable cities (Table 6) are associated with their designs, strategies, and policies in terms of development planning, which in turn shape and drive their operations, functions, and services in terms of operative management.

The pursuit of mastering the complexity of data mining and knowledge discovery processes for data-driven 


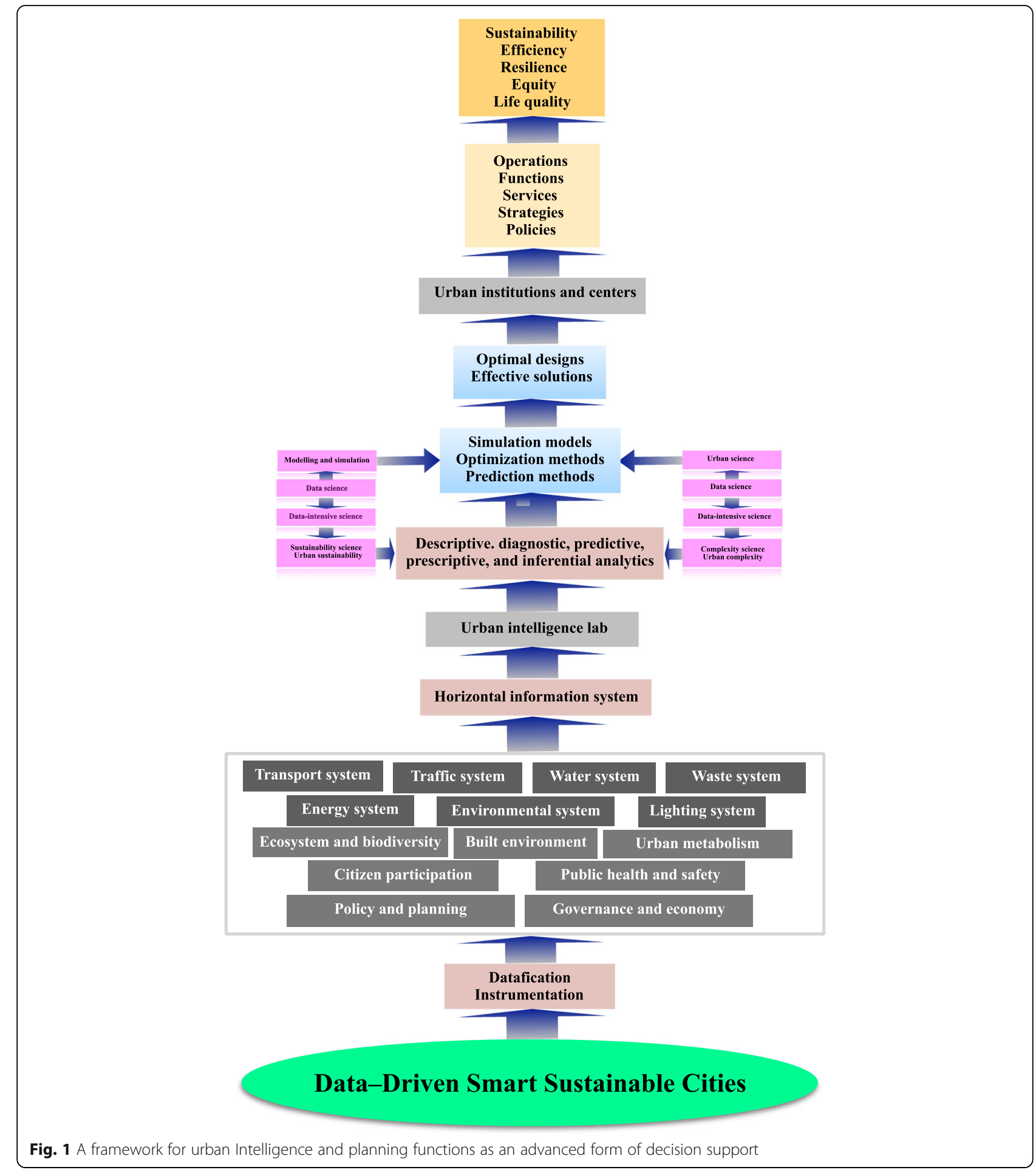

smart sustainable cities requires building an entirely holistic and integrated system of city analytics. The basic idea is to link the built environment (physical objects, energy system, water system, waste system, etc.) and the infrastructure passing into and out of urban areas (transportation systems, communication systems, distribution networks, etc) to their operational functioning and planning. This entails connecting unobtrusive and ubiquitous sensing technologies, advanced data management and analytics models, cooperative communication, novel visualization methods, and decision support systems. This is necessary for facilitating the development and implementation of urban intelligence and planning functions for improving and advancing sustainability. 
Table 6 Urban intelligence and planning functions for sustainability

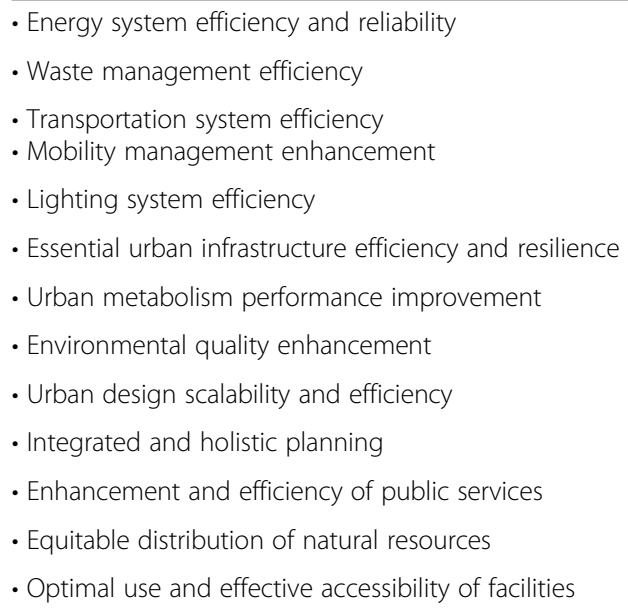

It is important to advance knowledge with respect to the different administration spheres of data-driven smart sustainable cities for the purpose of encompassing all the domains of data, patterns, and models. Of equal importance is to improve current methods for multilevel modelling and simulation by integrating and coordinating the diverse, hitherto unconnected, domains of sustainable cities based on data-driven technologies. Datadriven smart sustainable cities should focus on developing new models in various urban domains that pertain to the new kinds of data and movements and activities that are largely operated over multiple digital networks while concurrently relating these to traditional movements and locational activities. Critical to that focus is clear conceptions of how these models can be used to inform the planning and design of data-driven smart sustainable cities at different scales and over different time periods. This pertains particularly to the three dimensions of sustainability and their balanced integration. New forms of integrated and coordinated decision support systems should also be envisaged as part of urban intelligence and planning functions for the joined-up planning related to the landscape of data-driven smart sustainable cities. This comprises five dimensions: (1) technological infrastructure, (2) built infrastructure, (3) sustainable urban infrastructure, (4) smart urban infrastructure, and (5) social infrastructure. These are derived from the four cases studies conducted on compact cities, smart eco-cities, data-driven smart cities; and environmentally data-driven smart sustainable cities. As to the institutions into which the urban intelligence and planning functions should be woven, they should undergo major transformations. Bibri (2021b) identifies and distils the key institutional transformations required for advancing and balancing the three goals of sustainability and enabling the adoption of applied technology solutions in city development planning and operational management.

The five dimensions targeted by urban intelligence and planning functions are presented next. Except for the technological infrastructure, which is described in more detail due to its relation to urban computing and intelligence, the other infrastructures are only introduced together with the associated strategies and substrategies (together with a descriptive account of key systems and models). For a detailed description of all infrastructures as well as the strategic pathways to bring about the associated transformations, the interested reader might be directed to Bibri and Krogstie (2021).

\subsubsection{Technological infrastructure}

Generally, an ICT infrastructure includes hardware, software, networking, data storage, as well as an operating system. These are used to deliver applications and services to the different stakeholders of the city through its agencies and departments. The ICT infrastructure can be deployed within the city's own facilities or within cloud computing. The ICT infrastructure of data-driven smart sustainable cities of the future should be able to integrate numerous application domains for sustainability and thus comprise a wide range of solutions for various spheres of their administration. Moreover, it should demonstrate the innovative use and integration of the IoT, Device to Device (D2D), Clouds of Things, big data analytics, and Artificial Intelligence associated with urban computing and intelligence to solve the problems related to city operational management and development planning. The ICT infrastructure strategy includes the following substrategies:

- Sensor infrastructure and digital network for data transfer

- IT architecture layers

- Data sources and open data

The competencies associated with the ICT infrastructure pertain to the process of big data analytics in terms of generating, processing, analyzing, and visualizing data for enhancing decision making across the various domains of the city (transport, traffic, energy, environment, healthcare, public safety, etc.). They depend on the scale and quality of the instrumentation, datafication, and computation dimensions of the city. This in turn determines the nature and range of the solutions provided to optimize, enhance, and maintain the performance of the city with regard to sustainability. Digital instrumentation produces huge amount of data, which are transformed into datasets and thus become easily conjoined and shared and highly appropriate for handling. These datasets allow real-time analysis of the different aspects of 
urbanity to generate deep insights that can be used in decision-making processes and in developing simulation models for managing, planning, and designing more sustainable cities. The essence of digital instrumentation lies in coordinating and integrating technologies (and hence the strategies of sustainable cities and the solutions of smart cities) that have clear synergies in their implementation within development planning and operational management. This opens up and enables realizing many new opportunities in the context of sustainability.

Open sources characterize the availability of the actually used and potentially to be used sources of data. Based on the analysis of these data, data-driven smart sustainable cities of the future will be able to make countless and support complex decisions pertaining to planning, design, and operational functioning. However, some data are open and thus accessible to the public for use, while other data are confidential and thus pose privacy issues. Also, some data are available virtually for free, while other data require effort to obtain. Still not all the data needed for the development and implementation of applied data-driven solutions for sustainability exist.

\subsubsection{Built infrastructure}

\subsubsection{Compact design strategies \\ - Compactness \\ - Density \\ - Multidimensional mixed-land use \\ - Sustainable transportation \\ - Green open space.}

\subsubsection{Ecological design strategies \\ - Greening \\ - Rainwater harvesting \\ - Ecological diversity \\ - Biodiversity \\ - Green parks \\ - Green streets and alleys \\ - Green factor and green points \\ - Green roofs and rain gardens \\ - Bioswales and permeable pavements}

\subsubsection{Essential urban infrastructure: smart and sustainable strategies}

\author{
5.3.3.1 Smart sustainable transportation \\ - Walking and cycling \\ - Public transport \\ - Car-pooling (biogas and electric) \\ - Electric vehicles \\ - Smart transport management \\ - Smart traffic management \\ - Smart mobility management
}

\subsubsection{Smart sustainable energy}

- Renewable energy sources and technologies

- Smart power grid and advanced metering infrastructure technologies

- Smart building technologies

- Smart home monitoring technologies

- Smart environmental monitoring technologies.

\subsubsection{Smart sustainable waste management \\ - Convenient and smart waste collecting system \\ - Vacuum waste chutes \\ - Food waste disposers \\ - Biogas digesters \\ - Wastewater and sewage treatment system \\ - Biological waste separation procedures}

\subsubsection{Smart environmental monitoring system Air} pollutants as atmospheric substances-especially anthropogenic-have negative impacts on the environment, as well as pose a high environmental risk to human health, so too is noise pollution, both direct and indirect. Noise pollution denotes harmful outdoor sound with road traffic being the major contributor. The demand for the smart systems that monitor the quality of the environment has increased due to the elevation of pollutants in the atmosphere. The rapid urbanization of the world leads to the environmental degradation of the air. Nonetheless, new and emerging technologies allow a real-time tracking capability of the different substances spread in the air, as well as applying preventive measures in a timely manner. Air pollution is due to several gases and dust, such as particulate matter (PM 2.5 and PM 10), Ozone (O3), Nitrogen Dioxide (NO2), Sulphur Dioxide (SO2), Carbon Monoxide (CO), and Carbon Dioxide (CO2). Because air pollution and Greenhouse Gases (GHG) emissions are often released from the same sources, curbing GHG emissions in an effort to slow climate change also reduces air pollutants, such as PM 2.5. Reducing these co-emitted air pollutants improves air quality and benefits human health. GHG emissions are mostly associated with energy and transport sectors. Therefore, one of the significant objectives of datadriven smart sustainable cities of the future is to achieve a healthy and hyper-connected city with limited GHG emissions where urban planning, the environment, and ICT infrastructures are fully integrated and characterized by productive neighborhoods. The focus should be on the impacts of energy consumption on the environment and on control over transport flows and their effects on the noise level.

5.3.3.5 Smart urban metabolism model Urban metabolism as a model is used to facilitate the description and analysis of the flows of the materials and energy in the 
city and their relationship with its infrastructure and activities. It refers to the total sum of the technical and socio-economic processes that occur in the city, resulting in the production of energy that enables it to grow and evolve, and the elimination of waste. As such, it serves to maintain the functional and evolutionary states of the city as a socio-technical organism. Looking at data-driven smart sustainable cities of the future through a metabolic lens, a framework through which to successfully model the flows of their systems becomes of high importance and interest. This helps to understand the relationship between human activities and the natural environment by studying the interactions of human systems and natural systems. Indeed, urban metabolism provides a platform through which the implications of the different dimensions of sustainability can be considered.

Underlying data-driven smart sustainable cities of the future as an integrated model of urbanism is the idea of relating the underlying metabolism structure to its operational functioning and planning through control, management, optimization, and enhancement. These technical processes should be based on powerful new forms of simulation models and optimization methods fashioned by urban intelligence and planning functions. Especially, the pragmatic framework for urban metabolism used by systems scientists for promoting the concept of urban sustainability has a number of limitations that need to be overcome, including high data and resource requirement, lack of follow-up and evaluation of the evolution of the city's metabolism, difficulties in identifying cause-and-effect relationships of the metabolic flows, and lack of data on energy and material flows. Smart urban metabolism uses advanced data analytics techniques to assess and sustain the required level of sustainability by computing the ecological footprint and then identifying and suggesting alternative routes of development to reduce it. This relates to the concepts of ecosystem services, urban technical systems, and sustainability principles, as well as to the distribution of functions and population in the city.

5.3.3.6 Smart street lighting system The city-wide street lighting system provides tremendous opportunities for modern cities to collect huge amounts of data from urban environments and to transfer them to special centers for their subsequent processing and analysis for enhancing decision making associated with numerous uses and applications. This can be used to make urban living more environmentally sustainable and to enhance the quality of life for citizens. Street lighting is one of the most interesting pathway to using and exploiting the IoT and big data analytics in future cities. Thus, it can be expanded beyond what is originally used for.

5.3.3.7 Smart urban infrastructure management Advanced ICT will be focussed on defining critical problems and events that might emerge rapidly and unexpectedly across the city. Analysing and identifying such problems and events is of great importance to urban sustainability and resilience. The smart management of the essential urban infrastructure involves monitoring and controlling its structural conditions in terms of potential changes that can increase risks and hazards as well as compromise safety and quality. In this context, data-driven smart technologies and solutions tend to be mostly justified by the high significance of the natural resources such infrastructure utilizes or involves in its operation.

\subsubsection{Social infrastructure}

- Smart citizens: participation and consultation

- Smart public safety

- Smart healthcare

\section{Discussion}

Based on case study research together with related literature review performed on the prevailing paradigms of sustainable urbanism and the emerging paradigms of smart urbanism, the recent advances in urban computing and intelligence offer innovative approaches to urban planning enabled by data-driven technologies. Such approaches are necessary for the development and design of data-driven smart sustainable cities of the future as an integrated model comprising the dimensions, strategies, and solutions of these paradigms. The innovative potential of these approaches lie in advancing strategic sustainable urban planning and in enabling the short-term and joined-up forms of planning.

While strategic planning cannot reproduce the design characteristics of sustainable cities that have been developed based on incremental and interactive processes involving many stakeholders over time, the primary role of big data lies in enabling information flows and channels, coordination mechanisms, cooperative communication, learning and sharing processes involving divergent constituents and heterogenous collective and individual actors as data agents, and, above all, well-informed and fact-based decisions. These are, in fact, the most significant challenges facing sustainable cities, coupled with the dispersion of power. In particular, however, the relationship between urban planning and urban design interventions and sustainable development objectives is a subject of much debate. This means that realizing sustainable cities requires making countless decisions about 
urban form, design features, sustainable technologies, and governance. Making these decisions occurs through a social process consisting of complex negotiations and often disputes, thereby the relevance of fact-based and well-informed decisions. In this regard, the analytical outcome of big data can be used as the evidence base for formulating the policies, plans, and strategies of sustainable cities and tracking their impact and effectiveness, with the aim to improve or change them according to new trends, demands, and structural conditions. Adding to this is modeling and simulating future development projects and generating the designs and responses characterizing the operations and functions of sustainable cities. Both of these data-driven solutions are at the core of joined-up planning and short-term planning respectively. The big data deluge produced by sensing technologies and large-scale computing infrastructures provide rich knowledge about how sustainable cities function and can tackle complex challenges within the framework of data-driven smart sustainable cities of the future.

Cities growing ever bigger and faster in terms of their populations and knowledge base lie at the core of data-driven smart sustainable cities of the future. Advanced ICT holds the key to a desirable future, and it will be most clearly demonstrated in large sustainable cities. There are a number of technology innovations that have inspired the academic and practical endeavor of integrating sustainable cities and smart cities. First and foremost, advanced ICT is founded on the application of computer science, information science, data science, urban science, complexity science (e.g., Batty et al., 2012; Bettencourt, 2014; Bibri, 2019b; Kitchin, 2014, 2016), sustainability science, urban sustainability science, and dataintensive science (Bibri, 2019c, 2021c) to urban problems. And urban systems are in and of themselves becoming ever more complex through the technologies being used to understand them. This is due to the advent of new modes of real-time functioning of cities. The research project of developing a novel model for data-driven smart sustainable cities of the future is at the forefront of understanding complex systems using the very technologies that are fashioning and shaping those urban systems in the first place. Big data science and analytics is changing the very science that has been used for many decades, giving rise to a new scientific paradigm known as data-intensive science which is revolutionising many city-related disciplines and fields. Data-driven smart sustainable cities of the future will change the very nature of the adoption process by using that same technologies for the purpose of improving and advancing sustainability in terms of its three dimensions and their synergistic effects and balanced integration.
Underlying data-driven smart sustainable cities is the idea of, first and foremost, finding and applying innovative solutions for solving the problems, issues, and challenges facing sustainable cities (see Bibri, 2021a for a detailed review). This involves short-term and joined-up forms of planning as enabled by urban computing and intelligence and its technologies, techniques, models, as well as functions. Urban computing and intelligence may overcome one of the scientific challenges pertaining to sustainable cities-relating their built infrastructure, urban infrastructure, economic infrastructure, and social infrastructure to their operational functioning and development planning through control, management, optimization, and enhancements. This will enable sustainable cities to leverage their collective intelligence in making actual progress towards integrating and balancing the dimensions of sustainability. This is owing to the core enabling and driving technologies of big data computing offered by smart cities in relation to or for sustainability (e.g., Angelidou et al. 2017; Bibri, 2019a; Bibri \& Krogstie, 2020b, 2020c; Nikitin et al., 2016; Perera, Qin, Estrella, Reiff-Marganiec, \& Vasilakos, 2017; Petrovic'and Kocic' 2020; Stübinger \& Schneider, 2020; Thakuriah, Tilahun, \& Zellner, 2017; Toli \& Murtagh, 2020; Trencher, 2019).

Advanced ICT is being fast embedded into the very fabric of sustainable cities, fostered by the widespread diffusion of wireless technologies allowing for sensing and collecting massive repositories of various forms of data for large-scale analytics and decision-making. At the same time, developments in algorithmization, datafication, and computation to inform the planning and design of sustainable cities are increasingly using these same technologies. Such developments are being integrated so that sustainable cities can become truly smart in the way their planners can use such technologies to continuously contribute to sustainability. This involves conceiving sustainable cities in terms of the outcomes of urbanization rather than forms. This conception holds great potential for attaining the elusive goals of sustainable development, as this involves addressing the right question of whether the processes of building, living, producing, consuming, and moving are actually sustainable (Neuman, 2005). The indeterminacy of sustainability requires much more than settling for the form of the city, the structure of immutable order as a way to reduce uncertainty. As argued by Durack (2001), adopting sustainability as a sincere objective requires planning and designing cities "not only in closer correspondence with nature, but also in recognition of the process of life itself." Indeterminacy is at the heart of urban intelligence and planning functions as a process of understanding the functioning of data-driven smart sustainable cities of the future in the sense of the common scientific and 
mathematical concepts of uncertainty and their implications pertaining to big data science and analytics. Big data computing combines large-scale computation, new data-intensive techniques and algorithms, and advanced mathematical and Artificial Intelligence models to build and perform data analytics.

Comprehensive planning remains practically impossible, especially in large sustainable cities, due to the kind of complexities they embody. Nevertheless, big data technologies can play a pivotal role in providing the scale of knowledge of the consequences of interventions that can be practically useful for planning sustainable cities. The dynamical processes in sustainable cities as self-organizing social networks and dynamically changing environments must rely on the general principles that enforce necessary conditions so as to operate, organize, and evolve, and such ideas "are the core of developing scientific theory of cities, which is enabled by the growing availability of quantitative data on thousands of cities worldwide, across different geographies and levels of development" (Bettencourt, 2014, p. 12). The quantitative data in urban science relates to the datafication of cities, an urban trend that defines the key to core city operations and functions through a reliance on big data computing as part of urban computing. It is about turning many aspects of urban life into computerized datasets, converting data into a form that is stored, processed, and analyzed to extract useful knowledge. Datafication, according to Cukier and MayerSchönberger (2013), is the transformation of social action into online quantified data, thus allowing for realtime tracking and predictive analysis. The intensification of datafication is manifested in the radical expansion in the volume, range, variety, and granularity of the data generated about urban environments and citizens (Crawford \& Schultz, 2014; Kitchin, 2016; Strandberg, 2014). As organized in databases, the data regarding the different aspects of urbanity become easily conjoined, scalable, shared, and highly relevant for data analytics for further exploration related to, for example, planning, development, design, and scientific discovery.

The extensive use of data-driven technologies in the domain of planning is making it possible to build models that are able to deal with short-term issues, such as how people move through cities, or long-term issues, such as land use and urban growth (Landis, 2012). Some recent models, which are able to use urban data across different spatial and temporal scales, merge much of the data being "generated in real time in cities with more traditional cross-sectional sources but built on simulations that link real time, more routine problems to longer term strategic planning and action" (Batty et al., 2012, p. 483). These developments are in response to the emerging shift the model of the city is undergoing in light of big data science and analytics. In this respect, advanced ICT has dramatically shifted this model in such that it is no longer predicated on the basis that the city is a stable unchanging physical structure, but rather as an entity that is more and more dominated by information flows reflecting the complexity of technical and socio-economic and technical processes occurring in urban spaces, with no physical traces. This entails the ability of building simulation models that can respond to different complexities new conceptions. This has been made possible by the availability of the vast troves of real-time, contextual, dynamic, and actionable data generated based on the whole complex of data sources, which is drastically changing the process of planning and decision.

In addition, With the variety, exhaustivity, resolution, flexibility, scalability, evolvability, and relationality of the data generated in cities, it has become possible to build powerful new forms of simulation models that enable a continuous form of planning thanks to the fine-grained, sensitive, and nuanced analysis that can take into account the various aspects of urban complexities. The kind of simulation models that data-driven smart sustainable cities of the future should build are those that grapple with these changes, and that have the potential to embrace the very different conceptions of the city as a dynamically changing environment and self-organizing social network embedded in space. This then changes the conception of the way the simulation models can be built that respond to the city as such. This in turn results in changing the process of planning and decision to embrace the ability to sense, understand, and analyze the city in real time. However, there will always be more new and different sources of data which need to be collected and conjoined, an issue that curtains the opportunity to explore the real potential of the aggregation of real-time data to deal with changes in data-driven smart sustainable cities of the future. Nonetheless, what new developments promise is an ability to have a real time view of changes at different spatial scales and over different time scales and to deal with them early on to mitigate the risks and unintended consequences of the actions and choices of urban actors with respect to sustainability.

\section{Conclusion}

The emerging data-driven technologies and solutions have become of critical importance to smart sustainable urbanism practices. Urban policies, plans, and strategies are increasingly devised and their effectiveness tracked based on data-driven evidence. This is in turn affecting the operating and organizing processes of urban systems thanks to the emerging engineering solutions underpinned by advanced computational data analytics. 
The aim of this study was to analyze the enabling role and innovative potential of urban computing and intelligence in the strategic, short-term, and joinedplanning of data-driven smart sustainable cities of the future. Four objectives were formulated to achieve this aim, namely:

1. Identify and describe the key strategic planning approaches associated with the built infrastructure of data-driven smart sustainable cities of the future in terms of its compact and ecological designs

2. Map these approaches to the urban fabrics identified based on empirical research and discuss the role of big data in strategic planning.

3. Identify and analyze the evolving innovative approaches to urban planning enabled by the recent advances in urban computing and intelligence.

4. Devise a framework for urban intelligence and planning functions as an advanced form of decision support.

The three strategic planning approaches identified and described are based on three planning types or their combination: (1) emergent compact urban form, which represents the outcome of planning by coding; (2) designed dispersed urban form, which represents the outcome of planning by design; (3) and designed compact urban form, which represents the outcome of planning by design-usually in combination with planning by development control. The six urban fabrics to which the strategic planning approaches were mapped are: central renewal area, inner city, strategic nodes, complemented and mixed areas, outer areas, and new districts. These were derived from the case studies conducted on compact cities and smart eco-cities. The primary role of big data in improving strategic sustainable planning relates to: land use, urban development, urban design, urban infrastructure, and urban intensification.

New circumstances require new responses with respect to the planning and design of sustainable cities and what they pose as enormous challenges for the conventional forms of simulation models and optimization methods due to the kind of wicked problems and complexities embodied in urban sustainability. Sustainable cities becoming data-driven smart is about being designed in ways that allow to monitor, understand, analyze, and plan their infrastructures and systems to improve and maintain their performance thanks to the recent advances in urban computing and intelligence. This will change the way sustainable cities can be planned across multiple spatial and time scales, raising the prospect of becoming smarter in the long term by continuous reflection in the short term. This pertains to monitoring, assessing, and optimizing their performance in ways that respond to urban growth, environmental pressures, and changes in socio-economic needs on a monthly, daily, or hourly basis. This will further be supported by joined-up planning thanks to its coordination and integration features. Indeed, envisaging data-driven smart sustainable cities of the future should focus on the components that make them function as a social organism. Central to this quest is the idea of advanced ICT penetrating wherever it can to improve the outcome of what can be enacted by different city stakeholders in regard to sustainability, efficiency, resilience, equity, and life quality. Such improvement is at the core of urban intelligence and planning functions, which play a pivotal role in facilitating and harnessing the synergies between the design strategies of sustainable cities and the solutions of smart cities through advanced simulation models and optimization methods that generate designs and responses that boost the benefits of sustainability as to its tripartite composition. Indeed, urban computing and intelligence bridge the gap between unobtrusive and ubiquitous sensing, intelligent computing, cooperative communication, and massive data management and analytics. This is to create novel solutions for sustainability by means of cloud and fog computing, the IoT, device to device (D2D) communication, data analytics techniques, Artificial Intelligence, simulation models, visual analytics methods, and decision support systems.

Big data analytics has made it possible to make evidence-based decisions in terms of policy and planning to improve sustainability. Using a data-driven scientific approach to investigate all available evidence can lead to policy and planning decisions that are more effective in achieving the desired outcomes of sustainability as decisions are based on accurate and meaningful information-well informed. Urban computing and intelligence provides the systematic and rational approach required for evidence-based decision making in terms of analyzing available evidence to inform the policymaking and planning processes. This approach to decision making involves putting the best available evidence from research at the heart of policy design and development planning and their implementation. The evidence-based approach to decision making strives to improve the efficiency and effectiveness of policymaking and planning processes by focusing on what works and what needs to be improved. Among the benefits of evidence-based approach to policymaking and planning are ensuring that policies and plans are responding to the real needs of citizens, highlighting the urgency of issues or problems which requires immediate attention, and enabling information sharing amongst different stakeholders in regard to best practices.

However, the uses of data-driven technologies come with perils and pitfalls. Bibri (2021a) provides a critical 
understanding of data-driven smart urbanism in terms of the associated risks and implications, raising several critical questions involving technocentric policies and technocratic governance, as well as other aspects of social and environmental sustainability. In addition to these concerns, smart urbanism remains selective, flawed, biased, normative, and politically inflected, although it purports to produce a commonsensical, neutral, apolitical, evidence-based form of urban planning and governance. Moreover, opening the notion of intelligence to contestation, Lynch and Del Casino Jr (2020) examine differing conceptions of intelligence and what they might entail with regard to how to approach the theorization of "smart" spaces. The authors argue for a view of intelligence as multiple, partial, and situated in and in-between spaces, bodies, objects, and technologies, as well as call for attentiveness to the ways in which particular intelligences are prioritized over others, which may be suppressed and neglected, through the production of smart spaces in the context of our rapidly changing understandings of the "humanness" of intelligence. All in all, while big-data technologies can bring numerous advantages to sustainable cities, it is equally important to acknowledge the fact that these advanced technologies can be problematic. Therefore, policymakers and planners should be careful when employing them.

\section{Code availability}

Not applicable.

\section{Author's contributions}

The author wrote the whole manuscript and read and approved the published version.

\section{Funding}

The author received no financial support for the research, authorship, and/or publication of this article.

\section{Availability of data and materials}

Not applicable.

\section{Declarations}

\section{Competing interests}

The author declared no potential conflicts of interest with respect to the research, authorship, and/or publication of this article.

Received: 8 February 2021 Accepted: 22 April 2021

Published online: 20 May 2021

\section{References}

Ahern, J. (2011). From fail-safe to safe-to-fail: Sustainability and resilience in the new urban world. Landscape and Urban Planning, 100(4), 341-343.

Ameer, S., \& Shah, M. A. (2018). Exploiting big data analytics for smart urban planning. In 2018 IEEE 88th Vehicular Technology Conference (VTC-Fall), Chicago, IL, USA (pp. 1-5) https://doi.org/10.1109/NTCFall.2018.8691036,

Angelidou, M., Psaltoglou, A., Komninos, N., Kakderi, C., Tsarchopoulos, P., \& Panori, A. (2017). Enhancing sustainable urban development through smart city applications. Journal Science Technology Policy Management, 9(2), 146169.

Batty, M. (2013). Big data, smart cities and city planning. Dialogues in Human Geography, 3(3), 274-279.
Batty, M., Axhausen, K. W., Giannotti, F., Pozdnoukhov, A., Bazzani, A., Wachowicz, M., Ouzounis, G., \& Portugali, Y. (2012). Smart cities of the future. The European Physical Journal Special Topics, 214, 481-518.

Batty, M., \& Marshall, S. (2012). The origins of complexity theory in cities and planning. In J. Portugali, H. Meyer, E. Stolk, \& E. Tan (Eds.), Complexity theories of cities have come of age (pp. 21-46). Springer Berlin Heidelberg.

Bettencourt, L. (2013). The kind of problem a city is. In D. Offenhuber \& C. Ratti (Eds.), Die Stadt Entschlusseln: Wie Echtzeitdaten Den Urbanismus Verandern: Wie Echtzeitdaten den Urbanismus Verandern (pp. 175-187). Birkhauser.

Bettencourt, L. M. A. (2014). The uses of big data in cities. Santa Fe Institute.

Bibri, S. E. (2018a). Smart sustainable cities of the future: the untapped potential of big data analytics and context aware computing for advancing sustainability. Berlin: Springer.

Bibri, S. E. (2018b). The loT for smart sustainable cities of the future: An analytical framework for sensor-based big data applications for environmental sustainability. Sustainable Cities and Society, 38, 230-253.

Bibri, S. E. (2018c). Systems thinking and complexity science and the relevance of big data analytics, intelligence functions, and simulation models. In Smart sustainable cities of the future. The urban book series. Springer https://doi.org/1 0.1007/978-3-319-73981-6_6.

Bibri, S. E. (2019). On the sustainability of smart and smarter cities in the era of big data: An interdisciplinary and transdisciplinary literature review. Journal of Big Data, 6(25), 2-64.

Bibri, S. E. (2019b). Advances in smart sustainable urbanism: Data-driven and data-intensive scientific approaches to wicked problems. In Proceedings of the 4th annual international conference on smart city applications, ACM, Oct $2-$ 4, Casablanca, Morocco.

Bibri, S. E. (2019c). The sciences underlying smart sustainable urbanism: Unprecedented paradigmatic and scholarly shifts in light of big data science and analytics. Smart Cities, 2(2), 179-213.

Bibri, S. E. (2020). Advances in the leading paradigms of urbanism and their amalgamation: Compact cities, eco-cities, and data-driven smart cities. Springer.

Bibri, S. E. (2020b). A methodological framework for futures studies: Integrating normative backcasting approaches and descriptive case study design for strategic data-driven smart sustainable city planning (Vol. 3, p. 31) https://doi. org/10.1186/s42162-020-00133-5.

Bibri, S. E. (2021a). Data-driven smart sustainable cities of the future: An evidence synthesis approach to a comprehensive state-of-the-art literature review. Sustainable Futures. https://doi.org/10.1016/j.sttr.2021.100047.

Bibri, S. E. (2021b). A novel model for data-driven smart sustainable cities of the future: The institutional transformations required for balancing and advancing the three goals of sustainability. Energy Informatics, 4, 4 https://doi. org/10.1186/s42162-021-00138-8.

Bibri, S. E. (2021c). The core academic and scientific disciplines underlying datadriven smart sustainable urbanism: an interdisciplinary and transdisciplinary framework. Comput Urban Sci, 1(1), 1-32 https://doi.org/10.1007/s43762-02100001-2.

Bibri, S. E., \& Krogstie, J. (2017). The core enabling technologies of big data analytics and context-aware computing for smart sustainable cities: A review and synthesis. Journal of Big Data, 4(38), 1-50.

Bibri, S. E., \& Krogstie, J. (2018). The big data deluge for transforming the knowledge of smart sustainable cities: A data mining framework for urban analytics. In Proceedings of the $3 d$ annual international conference on smart city applications, ACM, Oct 11-12, Tetouan, Morocco.

Bibri, S. E., \& Krogstie, J. (2020a). Smart eco-city strategies and solutions for sustainability: The cases of Royal Seaport, Stockholm, and Western Harbor, Malmö, Sweden. Urban Science, 11(6), 1-42.

Bibri, S. E., \& Krogstie, J. (2020b). The emerging data-driven smart city and its innovative applied solutions for sustainability: The cases of London and Barcelona. Energy Informatics, 3, 5 https://doi.org/10.1186/s42162-02000108-6.

Bibri, S. E., \& Krogstie, J. (2020c). Environmentally data-driven smart sustainable cities: Applied innovative solutions for energy efficiency, pollution reduction, and urban metabolism. Energy Informatics In press.

Bibri, S. E., \& Krogstie, J. (2020d). Data-driven smart sustainable cities of the future: A novel model of urbanism and its core dimensions, strategies, and solutions. The Journal of Futures Studies, 25(2), 77-94.

Bibri, S. E., \& Krogstie, J. (2021). A novel model for data-driven smart sustainable cities of the future: A strategic roadmap to transformational change in the era of big data. Future Cities and Environment, 7(1), 1-25. 
Bibri, S. E., Krogstie, J., \& Kärrholm, M. (2020). Compact city planning and development: Emerging practices and strategies for achieving the goals of sustainability. Developments in the Built Environment, 4, 1-2.

Cheng, J., Bertolini, L., Le Clercq, F., \& Kapoen, L. (2013). Understanding urban networks: Comparing a node-, a density- and an accessibility-based view. Cities, 31, 165-176.

Crawford, K., \& Schultz, J. (2014). Big data and due process: Toward a framework to redress predictive privacy harms. Boston College Law Review, 55, 93-128.

Cukier, K., \& Mayer-Schönberger, V. (2013). The rise of big data. Foreign Affairs, (May/June), 28-40.

Davoudi, S., Shaw, K., Haider, L. J., Quinlan, A. E., Peterson, G. D., Wilkinson, C., et al. (2012). Resilience: A bridging concept or a dead end? 'Reframing' resilience: Challenges for planning theory and practice interacting traps: Resilience assessment of a pasture management system in Northern Afghanistan Urban Resilience: What does it mean in planning practice? Resilience as a useful concept for climate change adaptation? The politics of resilience for planning: A cautionary note. Planning Theory \& Practice, 13(2), 299-333.

de Rubeis, T., Gentile, N., Smarra, F., D'Innocenzo, A., Ambrosini, D., \& Paoletti, D. (2020). A novel method for daylight harvesting optimization based on lighting simulation and data-driven optimal control. In V. Corrado, E. Fabrizio, A. Gasparella, \& F. Patuzzi (Eds.), Proceedings of building simulation 2019: 16th conference of IBPSA (Vol. 16, pp. 10361043) International Building Performance Simulation Association (IBPSA) 5112 p. 210494.

Ducruet, C. (2020). Urban network. AAG. International encyclopedia of geography. Wiley. https://doi.org/10.1002/9781118786352.wbieg2121 halshs-02955201.

Durack, R. (2001). Village vices: The contradiction of new urbanism and sustainability. Places, 14(2), 64-69.

Eom, H.-J., \& Cho, G.-H. (2015). Exploring thresholds of built environment characteristics for walkable communities: Empirical evidence from the Seoul metro-politan area. Transportation Research Part D: Transport and Environment, 40, 76-86.

Estiri, H. (2017). Energy planning in a big data era: A theme study of the residential sector. In P. Thakuriah, N. Tilahun, \& M. Zellner (Eds.), Seeing cities through big data. Springer geography. Springer https://doi.org/10.1007/ 978-3-319-40902-3_13.

Gianni, D., D'Ambrogio, A., \& Tolk, A. (2014). Modeling and simulation-based 3015 systems engineering handbook (1st ed.). CRC Press.

Grinberger, A. Y., Lichter, M., \& Felsenstein, D. (2017). Dynamic agent based simulation of an urban disaster using synthetic big data. In P. Thakuriah, N. Tilahun, \& M. Zellner (Eds.), Seeing cities through big data. Springer geography. Springer https://doi.org/10.1007/978-3-319-40902-3_20.

Gunderson, L. H., \& Holling, C. S. (2002). Panarchy: Un- derstanding transformations in human and natural systems. Island Press.

Haettenschwiler, P. (1999). Neues anwenderfreundliches Konzept der Entscheidungsunterstützung. Gutes Entscheiden in Wirtschaft, Politik und Gesellschaft (pp. 189-208). vdf Hochschulverlag AG.

Hakpyeong, K., Heeju, C., Hyuna, K., Jongbaek, A., Seungkeun, Y., \& Taehoon, H. (2021). A systematic review of the smart energy conservation system: From smart homes to sustainable smart cities. Renewable and Sustainable Energy Reviews, 140, 110755.

Hayek, F. (1978). The results of human action but not of human design. In New studies in philosophy, politics, economics (pp. 96-105). University of Chicago Press.

Homer-Dixon, T. (2011). Complexity science. Oxford Leadership Journal, 2(1), 1-15. Inam, A. (2013). Designing urban transformation. Routledge.

Jacobs, J. (1961). The death and life of great American cities. Random House.

Ji, S. G., Zheng, Y., \& Li, T. R. (2016). Urban sensing based on human mobility. In Proceedings of the 18th ACM International Conference on Ubiquitous Computing (UbiComp 2016) (pp. 1040-1051).

Khan, Z. H., \& Gulliver, T. A. (2018). A macroscopic traffic model for traffic flow harmonization. European Transport Research Review, 10, 2.

Kitchin, R. (2014). The real-time city? Big data and smart urbanism. Geographical Journal, 79, 1-14

Kitchin, R. (2016). The ethics of smart cities and urban science. Philosophical Transactions of the Royal Society A, 374, 1-15.

Landis, J. D. (2012). Modeling urban systems. In R. Weber \& R. Crane (Eds.), The Oxford handbook of urban planning (pp. 323-350). Oxford University Press ISBN 978-0-19-537499-5.

Larice, M., \& MacDonald, E. (Eds.). (2007). The urban design reader. Routledge.
Li, D., Lin, C., Gao, W., Chen, Z., Wang, Z., \& Liu, G. (2020). Capsules TCN Network for Urban Computing and Intelligence in Urban Traffic Prediction. Wireless Communications and Mobile Computing Volume, 2020, 15, 6896579 https:// doi.org/10.1155/2020/6896579.

Liu, W., Cui, P., Nurminen, J. K., \& Wang, J. (2017). Special issue on intelligent urban computing with big data. Machine Vision and Applications, 28, 675-677 https://doi.org/10.1007/s00138-017-0877-8.

Lu, Y., Scott, A., Kim, J., Curi, C. B., McCarty, J., Pardy, A., et al. (2021). Integration of an energy- Economy model with an urban energy model. Buildings and Cities, 2(1), 114-133 https://doi.org/10.5334/bc.71.

Lynch, C. R., \& Del Casino Jr, V. J. (2020). Smart spaces, information processing, and the question of intelligence. Annals of the American Association of Geographers, 110(2), 382-390.

Manesh, S. V., \& Tadi, M. (2011). Sustainable urban morphology emergence via complex adaptive system analysis: Sustainable design in existing context. Procedia Engineering, 21, 89-97.

Marshall, S. (2012). Planning, design and the complexity of cities. In J. Portugali, H. Meyer, E. Stolk, \& E. Tan (Eds.), Complexity theories of cities have come of age (pp. 191-206). Springer.

Merlino, K. R. (2011). Urban grain and the vibrancy of older neighbourhoods: Metrics and measures. In Considering research: Reflecting upon current themes in architectural research (pp. 477-488). Lawrence Tech University.

Neuman, M. (2005). The compact city fallacy. Journal of Planning Education and Research, 25, 11-26.

Nigel, T. (1998). Urban planning theory since 1945 (pp. 3-4). Sage ISBN 978-0-76196093-5.

Nigel, T. (2007). Urban planning theory since 1945. Sage.

Nikitin, K., Lantsev, N., Nugaev, A., \& Yakovleva, A. (2016). Data-driven cities: From concept to applied solutions. Pricewater- houseCoopers (PwC) http://docpla yer.net/50140321-From-concept-to-applied-solutions-data-driven-cities.html.

Pasichnyi, O., Levihn, F., Shahrokni, H., Wallin, J., \& Kordas, O. (2019). Data-driven strategic planning of building energy retrofitting: The case of Stockholm. Journal of Cleaner Production, 233, 546-560.

Pasichnyi, O., Wallin, J., Levihn, F., Shahrokni, H., \& Kordas, O. (2019). Energy performance certificates - New opportunities for data-enabled urban energy policy instruments? Energy Policy, 127, 486-499.

Perera, C., Qin, Y., Estrella, J. C., Reiff-Marganiec, S., \& Vasilakos, A. V. (2017). Fog computing for sustainable smart cities: A survey. ACM Computing Surveys, 50(3), 1-43.

Petrovic, N., \& Kocic, Đ. (2020). Data-driven framework for energy-efficient smart cities. Journal Electric Engineering, 17, 41-63.

Power, D. J. (2002). Web-based and model-driven decision support systems: Concepts and issues. In Proceedings of the Americas conference on information systems, Long Beach, California.

Qin, P., \& Nishii, R. (2015). Statistical prediction of Dst index by solar wind data and \$t\$-distributions. IEEE Transactions on Plasma Science, 43(11), 3908-3915.

Rathore, M. M., Ahmad, A., Paul, A., \& Rho, S. (2016). Urban planning and building smart cities based on the internet of things using big data analytics. Computer Networks, 101, 63-80.

Rittel, H. W. J., \& Webber, M. M. (1973). Dilemmas in a general theory of planning. Policy Sciences, 4, 155-169.

Rowley, A. (1994). Definitions of urban design: The nature and concerns of urban design. Planning Practice and Research, 9(3), 179-197.

Sarkar, S., Chawla, S., Ahmad, S., et al. (2017). Effective urban structure inference from traffic flow dynamics. IEEE Transactions Big Data, 3(2), 181-193.

Scheurer, J. (2007). Compact city policy: How Europe re- discovered its history and met resistance. The Urban Reinventors, 2 Retrieved from http://www.urba nreinventors.net/2/scheurer/scheurer-urbanreinventors.pdf.

Shahrokni, H., Årman, L., Lazarevic, D., Nilsson, A., \& Brandt, N. (2015). Implementing smart urban metabolism in the Stockholm Royal Seaport: Smart city SRS. Journal of Industrial Ecology, 19(5), 917-929.

Shahrokni, H., Levihn, F., \& Brandt, N. (2014). Big meter data analysis of the energy efficiency potential in Stockholm's building stock. Energy and Buildings, 78, 153-164.

Shahrokni, H., van der Heijde, B., Lazarevic, D., \& Brandt, N. (2014). Big data GIS analytics towards efficient waste management in Stockholm. In ICT4S-ICT for sustainability. Atlantis Press.

Silva, B. N., Khan, M., Jung, C., Seo, J., Muhammad, D., Han, J., Yoon, Y., \& Han, K. (2018). Urban planning and smart city decision management empowered by real-time data processing using big data analytics. Sensors, 18, 2994 https:// doi.org/10.3390/s18092994. 
Sinaeepourfard, A. J., Garcia, X. M.-B., Marín-Tordera, E., Cirera, J., Grau, G., \& Casaus, F. (2016). Estimating smart city sensors data generation current and future data in the city of Barcelona. In Proceedings of conference: The 15th IFIP annual Mediterranean ad hoc networking workshop.

Späth, P. (Ed.). (2017). Smart -eco cities in Germany: Trends and city profiles. University of Exeter (SMART -ECO Project).

Sprague, R. (1980). A framework for the development of decision support systems. MIS Quarterly, 4(4), 1-25.

Sprague, R. H., \& Carlson, E. D. (1982). Building effective decision support systems, Prentice-Hall.

Strandberg, K. L. (2014). Monitoring, datafication and consent: Legal approaches to privacy in the big data context. In J. Lane, V. Stodden, S. Bender, \& H. Nissenbaum (Eds.), Privacy, big data and the public good (pp. 5-43). Cambridge University Press.

Stübinger, J., \& Schneider, L. (2020). Understanding smart city—A data-driven literature review. Sustain, 12, 8460 https://doi.org/10.3390/su12208460.

Sun, Y., \& Du, Y. (2017). Big data and sustainable cities: Applications of new and emerging forms of geospatial data in urban studies. Open Geospatial Data, Software and Standards, 2, 24 https://doi.org/10.1186/s40965-017-0037-0.

Thakuriah, P., Tilahun, N., \& Zellner, M. (2017). Seeing cities through big data research, methods and applications in urban informatics. Springer International Publishing.

Thornbush, M., \& Golubchikov, O. (2019). Sustainable urbanism in digital transitions: From low carbon to smart sustainable cities. Springer https://doi. org/10.1007/978-3-030-25947-1.

Toli, A. M., \& Murtagh, N. (2020). The concept of sustainability in Smart City definitions. Frontiers in Built Environment, 6, 77 https://doi.org/10.3389/fbuil.2 020.00077.

Tomor, Z., Meijer, A., Michels, A., \& Geertman, S. (2019). Smart governance for sustainable cities: Findings from a systematic literature review. Journal of Urban Technology, 26(4), 3-27.

Trencher, G. (2019). Towards the Smart City 2.0: Empirical evidence of using smartness as a tool for tackling social challenges. Technological Forecasting and Social Change, 142, 117-128 https://doi.org/10.1016/j.techfore.2018.07.033.

Wang, X. X., Xu, L. H., \& Chen, K. X. (2019). Data-driven short-term forecasting for urban road network traffic based on data processing and LSTM-RNN. Arabian Journal for Science and Engineering, 44(4), 3043-3060.

Xu, T., Han, G., Qi, X., Du, J., Lin, C., \& Shu, L. (2020). A hybrid machine learning model for demand prediction of edge-computing-based bike-sharing system using internet of things. IEEE Internet of Things Journal, 7(8), 7345-7356 https://doi.org/10.1109/JOT.2020.2983089.

Yigitcanlar, T., \& Cugurullo, F. (2020). The sustainability of artificial intelligence: An urbanistic viewpoint from the Lens of smart and sustainable cities. Sustainability, 12, 8548.

Yin, R. K. (2014). Case study research: Design and methods. Sage.

Yin, R. K. (2017). Case study research and applications: Design and methods (6th ed.). SAGE Publications, Inc

Zhang, J. B., Zheng, Y., \& Qi, D. K. (2016). Deep spatio-temporal residual networks for citywide crowd flows prediction. In Proceedings of the 31st AAAl Conference on Artificial Intelligence.

Zheng, Y. (2017). Urban computing: Enabling urban intelligence with big data. Frontiers of Computer Science, 11, 1-3 https://doi.org/10.1007/s11704-0166907-2.

Zheng, Y., Capra, L., Wolfson, O., \& Yang, H. (2014). Urban computing: Concepts, methodologies, and applications. ACM Transactions on Intelligent Systems and Technology, 5(3), 222-235.

Zheng, Y., Yi, X. W., Li, M., Li, R. Y., Shan, Z. Q., Chang, E., \& Li, T. R. (2015). Forecasting fine-grained air quality based on big data. In Proceeding of the 21st SIGKDD Conference on Knowledge Discovery and Data Mining (KDD 2015) (pp. 2267-2276).

\section{Publisher's Note}

Springer Nature remains neutral with regard to jurisdictional claims in published maps and institutional affiliations. 